\title{
Reared to become wild-like: addressing behavioral and cognitive deficits in cultured aquatic animals destined for stocking into natural environments-a critical review
}

Department of Aquatic

Resources, Institute of

Freshwater Research, Swedish

University of Agricultural

Sciences, Drottningholm, Sweden

Email:<joacim.naslund@slu.se>

DEVELOPING AND INTEGRATING ENHANCEMENT STRATEGIES TO IMPROVE AND RESTORE FISHERIES

Proceedings of the 1oth FSUMote International Symposium on Fisheries Ecology and 6th International Symposium on Stock Enhancement and Sea Ranching

Guest Editors: Kai Lorenzen, Kenneth M Leber, Neil R Loneragan, Ryan W Schloesser, Matthew D Taylor

\section{Handling Editor: Kai Lorenzen}

Date Submitted: 31 May, 2020. Date Accepted: 16 September, 2021. Available Online: 17 September, 2021.

\author{
Joacim Näslund
}

\begin{abstract}
Hatchery-reared aquatic animals tend to perform worse in natural environments than wild conspecifics. This was pointed out over a century ago and while there are many possible causes, one persistent observation is that unnatural rearing environments cause behavioral expressions unsuitable for a life in the wild. Behavioral traits being adaptive in barren, food-rich, and predator-free hatchery tanks likely differ from those being adaptive in nature. More recently, suspicions of cognitive deficiencies due to sensory deprivation have also been raised. Over the last few decades, substantial research has been devoted to produce more wild-like phenotypes in animals reared for stocking. This research includes lifeskills training programs, where animals learn to cope with important features of the natural environment (e.g., live food and predation risk), and environmental modifications aimed at stimulating the formation of adequate cognitive and behavioral traits (e.g., environmental enrichment and reduction of the number of individuals per tank). The main purpose of this paper is to provide a summary of the current state-of-knowledge of interventions aimed at ameliorating cognitive and behavioral deficiencies in aquatic animals reared for stocking. Furthermore, it aims to provide a foundation to assist in the development of future questions, hypotheses, and experiments to eventually improve the postrelease performance of these animals.
\end{abstract}

"We have been too content with turning out a nice looking report of the number of fish hatched, reared, and presumably planted; and not sufficiently concerned with what actually happened to the fish afterward" - WM Keil 1935

Release of captive-reared aquatic animals into nature is a management practice that has been carried out for over a century, typically aimed at increasing stocks or establishing populations under the assumption that captive-rearing bypasses the natural early-life survival bottlenecks (Stickney 1994, Olla et al. 1998, Blaxter 2000, Crane and Mathis 2011, Daly et al. 2020, Östergren et al. 2021). Given the current 
anthropogenic pressure on aquatic ecosystems (Young et al. 2016), stocking and restocking of aquatic animals will likely continue to sustain and reestablish populations in nature. For some threatened species from highly impacted and geographically restricted environments, ex situ breeding and postrestoration restocking could become the only option left to avoid complete extinction (Stickney 1994, Marsh et al. 2005, Lema et al. 2021).

Animals growing up in captivity may develop traits, through plasticity or selection, that are suboptimal for a life in the natural environment (Johnsson et al. 2014, Gering et al. 2019). Considering behavioral traits, unequivocal results from previous research show that captive rearing can cause deviations from wild phenotypes (Einum and Fleming 2001, Orlov et al. 2006, Jonsson and Jonsson 2014, Crane et al. 2015), likely through several different routes (Fig. 1).

Maladaptive traits generated in captivity can be detected already in the first captive-reared generation (e.g., Araki et al. 2008, Christie et al. 2016, Fraser et al. 2019). Animals undergoing domestication selection (Teletchea 2021), whether intentionally or inadvertently, obtain traits favorable for good performance in aquaculture environments, which are not necessarily traits beneficial in the natural environment (Araki et al. 2008, Islam et al. 2020, Solberg et al. 2020). Selection on certain culturepromoted behavioral traits could also act on the animals without domestication playing a role. Given consistent differences in behavior among individuals (often termed "personality")—-developed through either genetic or plastic mechanisms - the traits of the cultured population can become biased through in-hatchery selective pressures (Fernö et al. 2011, Johnsson et al. 2014, Mittelbach et al. 2014). Thereby, the eventually released animals may consist of behavioral phenotypes that are suboptimal in the wild, even if individuals with wild-like traits originally existed in the population (e.g., in an F1 generation stemming from wild parents). Populations reared in captivity over several generations can be affected by relaxed selection pressures in the absence of natural risk-factors. If certain risk-coping behaviors are not necessary for survival in the captive environment, individuals expressing such behaviors will not be selected against, possibly leading to accumulation of traits and abnormalities that would be suboptimal or detrimental in the wild (Einum and Fleming 2001, Araki et al. 2008, Johnsson et al. 2014).

Low numbers of broodstock animals can lead to maladaptive phenotypes through inbreeding and limit the genetic and phenotypic variation in general (Wang et al. 2002, Araki et al. 2008). Evolutionary rescue, driven by natural selection in the release environment, may drive phenotypically altered stocked animals to regain nature-like phenotypes and increase fitness over generations (Hendry et al. 2018). However, it may not be feasible to rely on such multi-generational rescue effects in stocking-related management.

Even without any selection, e.g., when survival is 100\%, the captive-reared animals may have a general plastic response to the environment, or just flexibly learn to behave in a certain way, resulting in carry-over effects on their postrelease behavior (Johnsson et al. 2014). Phenotypic development is affected by several environmental factors (Daly et al. 2020), altering physiological and morphological traits (e.g., stamina, body condition, stress responsiveness, morphological defense structures, etc.), which in turn may affect behavior. Environmental factors could also affect general cognitive and behavioral traits through a more direct route, e.g., lack of sensory stimulation in barren tanks and lack of natural features like shelters, predators, and live food. 


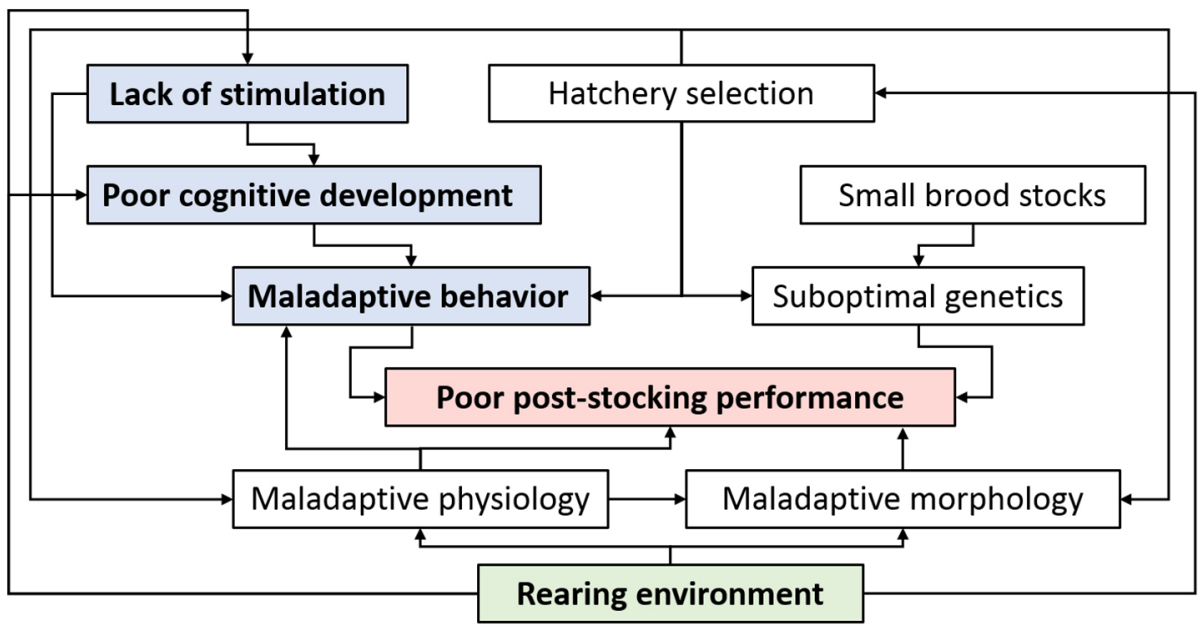

Figure 1. Flowchart illustrating the hypothetical causation of poor poststocking performance. Boxes with bold text are covered in this review.

Deficient behavioral traits being a problem in captive-reared aquatic animals is not a new revelation but has long been acknowledged and investigated (Keil 1935, Fortney 1939, Schuck 1948, Vincent 1960). Furthermore, even if behavior is not directly deficient under normal environmental conditions in the released individuals, a stock with biased phenotypes - un representative of the natural-population trait variation and niche breadth - could possibly be more sensitive to certain occasional stressors or lead to cascading ecological effects through the ecosystem (Mittelbach et al. 2014). Diversity in trait expression among individuals, even if plastically derived, can be an important aspect of biodiversity in an ecosystem and vital for postrelease success (Watters and Meehan 2007, Cordero-Rivera 2017).

Suboptimal performance would quite obviously be an issue for most stocking programs. While goals can differ markedly among different programs (see Cowx 1994, Lorenzen et al. 2012), most expect the animals to sustain themselves in a natural or seminatural environment over a substantial time-period, e.g., until reaching a catchable size (in fisheries enhancement stocking), until reproductive adulthood (in restocking, supplementation, and reintroduction stocking), or just as long as possible (in biomanipulation stocking). The exception may be stocking of catchable-sized fish for put-and-take angling in areas with high angling pressure, where exposure to angling-related disturbance can make the fish unwilling to take baits and hence make them progressively less valuable to managers over time (Koeck et al. 2019). Also, from a native-ecosystem conservation perspective, poor performance of stocked individuals may have saved many ecosystems and locally adapted populations from nonnative invasive species and introgression of foreign genes.

The problem of high mortality in stocked individuals may sometimes be approached by increasing the number of released animals, assuming that survival remains at similar levels regardless of the initial stocking density in a waterbody. Under certain circumstances it could possibly be true, but such practice could also lead to unwanted ecological effects as large numbers of stocked animals can influence natural populations and ecosystems negatively (McNeil 1991, Stickney 1994, Einum and 
Fleming 2001, Lorenzen et al. 2012, Cucherousset and Olden 2020). Initially, any ecological or organismal features being density-dependent are likely affected (Einum and Fleming 2001). Furthermore, stocked animals often represent a sudden input of energy into the system, a locally increased resource demand to sustain the new animals, and a possible attraction of predators to the stocking site (both animals and humans), all of which may influence the natural inhabitants at the site. A different solution, which is likely more sustainable from an ecosystem-based view, is to improve the stocking success by increasing the quality of the stocked animals by prestocking exposure to nature-like conditions (Tetzlaff et al. 2019). To successfully introduce cultured animals into the natural environment, the animals need to have, or quickly obtain, the "life-skills" or "ecological competence" necessary to survive, grow, and reproduce in the wild (Suboski and Templeton 1989, Daly et al. 2020). This includes skills associated with avoiding various predators, coping with complex surroundings, foraging on natural prey, and appropriately interacting with conspecifics (Henderson 1980, Kleiman 1989). Simply put, the aim is to rear animals with wildlike morphological, physiological, and behavioral phenotypes (Lorenzen et al. 2012, Daly et al. 2020).

\section{Review Aims and a Roadmap to the Paper}

This review focuses on the effects of artificial environments on behavior and cognition in aquatic animals and their poststocking consequences. There are several previous literature reviews on this subject; for an overview, these are outlined in Figure 2. The aims of the present review are (1) to present the relevance of considering behavior and cognition in the optimization of postrelease performance of stocked aquatic animals, (2) to present and critically discuss the literature investigating amelioration of cognitive and behavioral deficits in aquatic animals reared for stocking, and (3) to identify relevant areas for further scientific exploration in the light of previous studies. As with any broader-scope review, the journey through the information is long and convoluted. Hence, a short roadmap to the following sections is presented here:

- Definitions And Concepts.-Explanations to the key ethological concepts discussed in later sections. The definitions are aimed to provide insights into the concepts discussed but are not exhaustive. Complementary and additional information is found in animal behavior and cognition science textbooks.

- Postrelease Performance Issues.-The performance issues in natural environments, with examples of poor postrelease performance, a conceptual time-frame discussing when issues could be detected, and the main behavioral and cognitive deficiencies identified in previous research. The section also discusses the fact that some species, populations, and individuals may be more suitable for stocking than others ("stockability") due to differences in their plasticity and flexibility.

- Improving Postrelease Performance.-Possible solutions to improving postrelease performance. The potential solutions are grouped under overarching aims: antipredation training, foraging training, exposure to complex environments, and exposure to nature-like social environments. Results from studies using strategies with similar methodology are grouped under separate sub-headings. Since studies are commonly biased toward certain taxa, the 


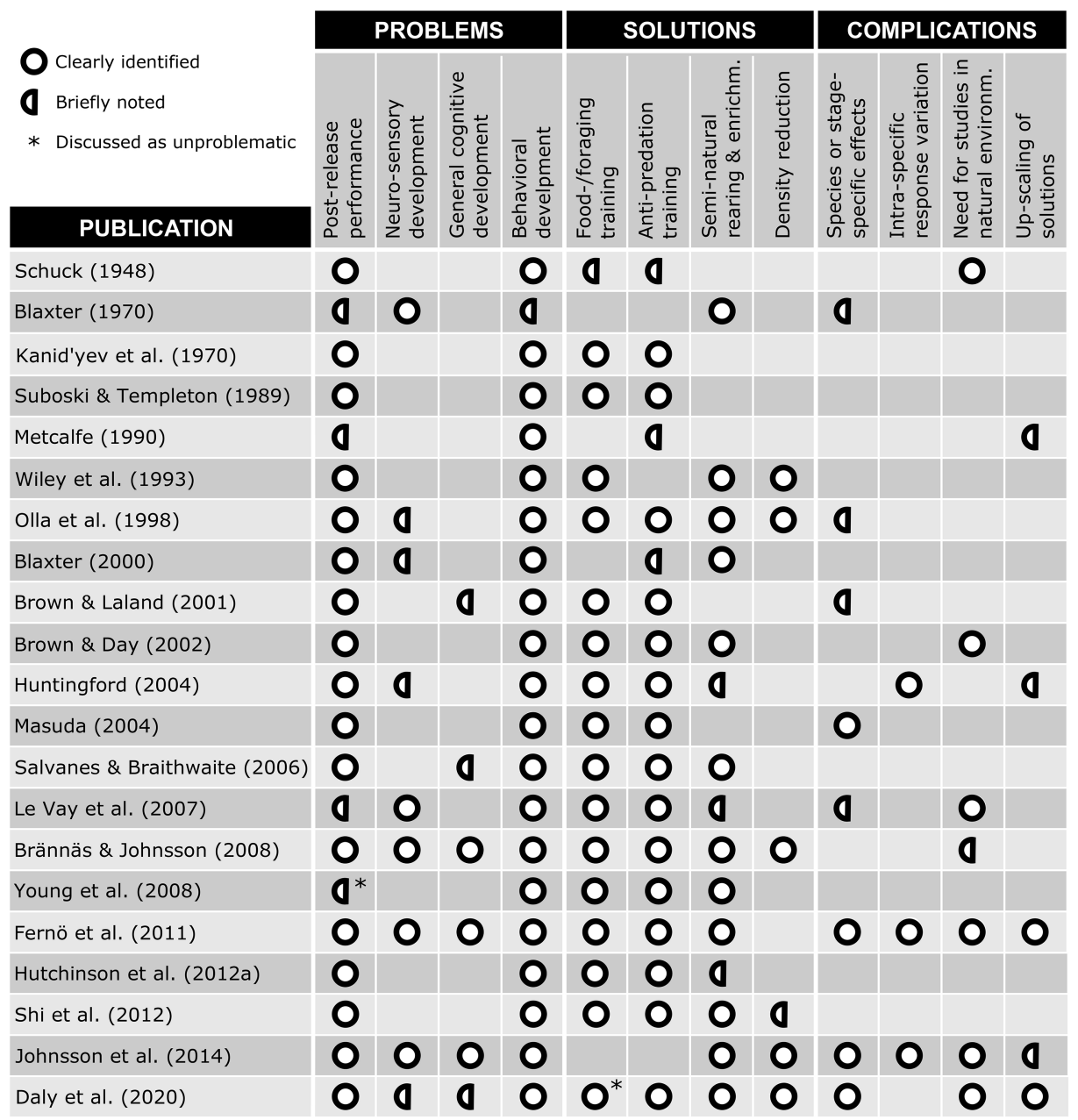

Figure 2. Brief summary of previous review articles on life-skills training in aquatic animals. The coverage of the different papers mainly reflects their aimed-at coverage and does not reflect negligence of certain topics.

results should preferably be viewed as merely indicative of potential effects. Even within a species or population, effects may be variable, and some published results can possibly be spurious. Furthermore, some expected improvements are only speculative, based on changes in behavior and cognition as assessed while the animals are still in the rearing facility. More detailed summaries of each reviewed study are found in a separate document in the figshare repository (see Online Supplementary Material).

- Discussion and Suggested Future Directions.-The article is concluded by a brief section discussing the general patterns in the literature review. Since this is not a meta-analysis, which would require more studies with comparable methodologies, the discussed patterns represent the main robust trends in the literature (as perceived by the author). A list of perceived information gaps is also presented as a suggestion for future research areas in the field. 
Due to the general focus of the published research to this date, this review predominantly covers studies on bony fish, particularly salmonids. Furthermore, the focus is primarily on animals reared in artificial environments; rearing in natural or seminatural ponds and lakes or enclosed natural areas is not covered. Animals reared extensively or semi-intensively in (semi-)natural systems would generally be expected to have more nature-like traits and higher postrelease performance than animals reared in intensive artificial systems. This has been demonstrated (e.g., Näslund 1992, Kelley et al. 2005), but counter examples also exist (Mundie et al. 1990, Turek et al. 2010). The former type of rearing could sometimes be an alternative to the latter, but it is not part of the scope of this review. Performance of fish in otherwise fish-free put-and-take systems, where continued sustenance of the stock is not an aim, is not a major focus area either.

\section{Definitions AND Concepts}

BEHAVIOR.-While "behavior" as a concept may seem intuitive, there is relevant debate about the definition. Here, the definition of Levitis et al. (2009) is used, where behavior is "the internally coordinated responses (actions or inactions) of whole living organisms (individuals or groups) to internal and/or external stimuli, excluding responses more easily understood as developmental changes." This definition excludes phenomena like growth, heart beats, hormone expression, and involuntary movements while including color changes, group formation, active movements, freezing of movements, reactions to stimuli, etc. Behaviors and preferences that are innate can be viewed as part of the phylogenetic memory (i.e., stored in the genome; Menzel et al. 2007). Innate behaviors can be plastic in response to the environment, through an evolved reaction norm (Stearns 1989), although some are not ("fixed action patterns"). Many behaviors are also flexibly modified by learning through experience, influenced by stimuli through the individual memory and coordinated with the phylogenetic memory (Kieffer and Colgan 1992, Menzel et al. 2007). Thereby, the environment typically affects behaviors through physiological and neurological mechanisms.

Cognition.-Cognition refers to all ways in which animals register and act on information, including perception, attention, processing, retention, and decisionmaking (Shettleworth 2001, Greggor et al. 2014). Information use is key to adaptive behavior, as accurate assessment of environmental parameters lets the animal adjust and meet demands of a variable world (Dall et al. 2005). Learning and memory, for instance, allow an animal to modify its behavior in relation to its experience. While there is substantial cognitive variation across species (e.g., Coble et al. 1985), studies of animal cognition are generally relevant regardless of a given species' neural complexity or degree of consciousness (Shettleworth 2001). In fact, animals historically classified as "simple" (e.g., invertebrates and fish) exhibit a wide range of behavioral and cognitive adaptations useful for survival and reproductive success (Menzel et al. 2007, Brown 2015). Like many other traits, cognitive traits can be responsive to environmental factors (Brockmark et al. 2010, Dalesman and Lukowiak 2011). However, different species are differently cognitively responsive to the environment and, in a simplified way, this can be explained by how their phylogenetic or individual memory interacts (Menzel et al. 2007). When phylogenetic memory dominates (expected in 
short-lived specialists from stable environments), the cognitive flexibility to environmental cues can be expected to be lower than when individual memory dominates (expected in longer-lived generalists living under highly variable conditions).

It is important to note that different taxa differ in their "umwelt" ("cognitive world"), which means that perception and interpretation of stimuli will differ among species, depending on the fact that their sensory systems are evolutionarily adapted to different environments (von Uexküll 1934, Greggor et al. 2014). Hence, different species may react differently to the same stimuli, and reactions may not always be intuitive to humans since the human umwelt differs from the animal's (Van Dyck 2012). Given plasticity and variation in the sensory modalities among conspecifics, the umwelt may also differ among individuals depending on their experience and sensory development. Knowledge about the animal's perceptual biases can aid in developing proper rearing and release strategies in stocking programs [see Greggor et al. (2014) for a guide on applying cognitive theory to address problematic behaviors].

As a baseline assumption, we can adopt the notion that learning and memory mechanisms are costly in terms of energy expenditure (e.g., Niven and Laughlin 2008, Burns et al. 2009, Brown et al. 2013a). Hence, it could be adaptive to not develop such traits more than necessary (Mery and Kawecki 2004) and, as a likely consequence of trade-offs between energy expenditure and cognitive complexity, cognitive abilities and behavior vary substantially both among and within species (Burns et al. 2009). This could hypothetically explain why cognitive function can be reduced in captive environments, as these are often very simple and monotonous and may require less information processing than natural environments.

Conditioning: Associative Learning Procedures.-The term "conditioning" is used in different ways in the literature concerning training of captive-reared animals for a life in the wild. One usage is to generally describe enforced prerelease acclimation or habituation to specific features of nature (e.g., shelters, natural substrates, or predator cues). Another usage is to strictly mean facilitated associative learning (or "predictive learning"), i.e., the way the term is used in cognitive sciences (e.g., Menzel et al. 2007, Fernö et al. 2011); this is the way the term is used in this review.

During conditioning an animal is learning to associate stimuli to events over repeated trials. The animal learns either to do something novel (or to improve on a task) or to stop expressing a behavior. Associative learning is a basal learning mechanism and found across a wide range of taxa. Conditioning procedures are typically divided into two general categories: classical conditioning and operant (or instrumental) conditioning (for more details on conditioning of fish and invertebrates, see Fernö et al. 2011 and Menzel et al. 2007, respectively).

Classical Conditioning.-Classical conditioning (Pavlov 1927) makes the animal associate environmental stimuli to each other, so that a neutral stimulus (NS; e.g., presence of sandy substrate) becomes associated to a biologically potent unconditioned stimulus (US; e.g., food items). The US evokes a behavioral reflex [the unconditioned response (UR); e.g., foraging behavior] that we eventually want as a response to the NS. After a number of trials where NS and US become associated, and thereafter the NS in itself will lead to the desired response. At that point, the previous NS has become a conditioned stimulus (CS) and the behavior resulting from it has become 
a conditioned response (CR; Fig. 3). Classical conditioning training can be either inhibitory (CS signals absence of US) or excitatory (CS signals occurrence of US). Importantly, the onset of CS typically needs to precede the onset of US to achieve successful conditioning, either using a delay procedure (cues overlapping slightly in time, or directly adjacent) or using a trace procedure (cues offset by a stimulus-free trace interval; Fernö et al. 2011). Simultaneous or reverse-order onset of stimuli often fails to elicit associations (Fitzwater and Reisman 1952).

Operational Conditioning.-Operational conditioning (Skinner 1938) makes the animal learn to associate its own behavioral action to a consequence, using either reinforcement (rewards) or punishment to strengthen and weaken associations (Fig. 3). Applied consequences are typically classified as either positive (adding a reward or punishment) or negative (removing a reward or punishment). In operant conditioning, a stimulus cue is used to incite the animal to perform an action, which is then rewarded or punished when performed. The method has been used for associative learning trials in fish, crustaceans, and mollusks (Wright and Eastscott 1982, Abramson and Feinman 1990, Rivi et al. 2021) but is typically not used in life-skills training for aquatic animals and will not be delved into further.

A relevant, but commonly omitted, feature of conditioning is the extinction of the CR (e.g., Tarrant 1964). Following the discontinuation of the pairing US and CS, the CR eventually decays as CS becomes uninformative in relation to what the animal has learnt to expect from the stimuli. Not remembering cues that stop being relevant may be beneficial to animals ("adaptive forgetting"; Brown et al. 2013a) and knowing the extinction rate of CR has relevance for the timing and background presence of cues used to condition animals for release into nature (see also Learning Curves section below). A similar concept, habituation, refers to non-associative learning and means that repeated exposure to a stimulus, particularly an inconsequential one, leads to a waned innate response to the stimulus (independent of sensory fatigue).

Another concept important to consider and evaluate in conditioning training of life-skills is generalization. Generalization is the ability to apply learned concepts and classification criteria across a wider context (e.g., to react with antipredation behaviors to a range of predators or foraging on a range of natural prey), not only to the stimulus used in training.

LEARNING CURVES.-When working with animal learning, it is useful to consider the concept of the learning curve, which visualizes the change in associative strength to a stimulus through consecutive trials. Learning curves are used to assess how many trials it takes to reach a threshold level (a level good enough to consider an animal having successfully learnt the association). The shape of the learning curve (Fig. 3) depends on several factors. The type and strength of the stimuli used (i.e., the salience, from the animal's umwelt perspective), the motivational state and attention of the animal, and previous experience will all affect the number of trials required to reach the threshold level (Warburton and Hughes 2011).

Theory from the perspective of associative learning states that the change in associative strength (i.e., the response to CS) from trial to trial is positively affected by associability of the CS; the stronger the CS associability is, the faster the animal will improve (Rescorla and Wagner 1972). Importantly, if the CS is not informative in a 

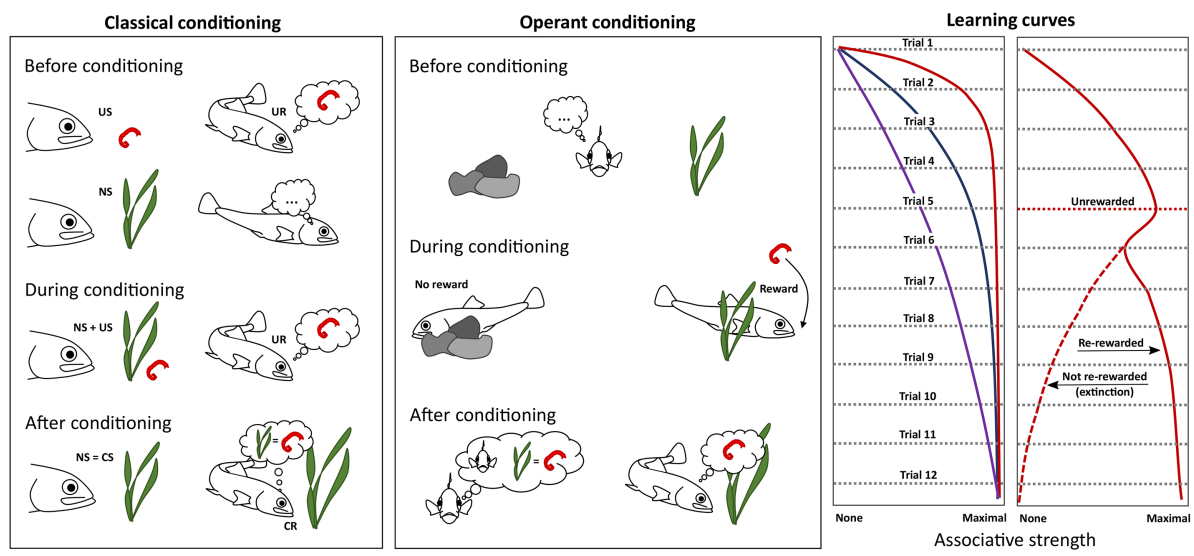

Figure 3. Illustration of the differences between classical (associating an unconditioned stimulus with a neutral stimulus to condition a desired response) and operant (rewarding actions to condition a desired response) conditioning, using a simple life-skills training example (conditioning usage of vegetated habitats with food as unconditioned stimuli/reward). Learning curves illustrate how different learning rates (depending on e.g., motivation or stimuli salience) affect the efficiency of training and numbers of trials required to reach a desired associative strength (left graph), and how either an unrewarded (e.g., a failed) trial or stopping rewards completely (hatched line) could affect associative strength (right graph). CR: conditional response, CS: conditional stimulus, NS: neutral stimulus UR: unconditional response, US: unconditional stimulus.

trial, no association can be made in that trial and the CS will lose in associability; in other words, the expectations of outcomes is continuously updated to adapt responses to stimuli (Fig. 3). Hence, if a given NS/CS is regularly present in the hatchery environment without any sign of the US, it will be harder to use it for conditioning. The salience of the US also has a positive effect on learning efficiency. If the US does not evoke a strong reaction, the training can be expected to be slower than if the reaction to US is strong. If the US is previously associated to a different behavior, it will be harder for the animal to re-associate it to a new behavioral response. Similarly, an NS that the animal has been previously exposed to typically takes longer to acquire meaning ("latent inhibition" or "learned irrelevance").

The maximum association strength is reached when the response to CS equals the response to US. Conditioning with two simultaneous CS can be inefficient in lifeskills training as the maximal association strength is reached when the combined associative strength equals CS; hence, this would end up with lower conditioning efficiency for both CS, and also lower final association strength for both of them, compared to if they were conditioned on their own.

\section{Postrelease Performance Issues}

Given that the release environment is suitable for the species and not already at carrying capacity, the parental stock does not have low viability (considering, for example, local adaptation and domestication), and the stocking is properly conducted, we could expect a relatively successful result. As a case in point, introductions of cultured aquatic animals into new areas are sometimes very "successful", causing invasions of nonnative species over large geographical areas (Havel et al. 2015). However, success clearly depends on species characteristics; while some species are easily established in certain environments, others are not. A summary of size-standardized 
mortality rates on fish indicated that wild populations on average show lower mortality rates than hatchery-reared fish; the latter, however, also show higher variation (Lorenzen 2006). Other studies, on both fish and invertebrates, often confirm the picture of higher mortality rates in cultured animals compared to wild age, stage, and size-matched conspecifics (Einum and Fleming 2001, Bell et al. 2005, Marsh et al. 2005, Araki et al. 2008, Daly et al. 2020). Notably, the substantial variation in mortality in stocked animals is also supported, as there are several cases where there is no appreciable difference between wild and hatchery-reared animals (e.g., Svåsand et al. 1998, Støttrup et al. 2002, Young et al. 2008, Moore et al. 2012, Lebata-Ramos et al. 2013).

A striking example of postrelease performance issues comes from Atlantic salmon (Salmo salar) in the Baltic Sea, where median marine survival chance of stocked individuals has been estimated to be lower than in wild individuals every single year between 1987 and 2018 (ICES 2019). This is not to say that the stocked salmon do not survive, because some obviously do. This can be seen around the Baltic Sea, where the salmon populations have been genetically homogenized due to salmon with different origins being transferred among rivers within the basin (Östergren et al. 2021). As another example, postrelease survival of hatchery-reared and wild queen conch (Strombus gigas) was 9\% and 28\%, respectively, after 7 months, with lower predation mortality of wild conch also being demonstrated in tethering experiments (Stoner and Davis 1994). Mortality mainly occurred within the first couple of months postrelease, suggesting that conch eventually adapt to natural conditions and predation, unless this pattern is driven solely by selective pressures on innate behavior (see below).

The Postrelease Survival Time Course.-A general postrelease mortality pattern starts with a conspicuously high mortality rate, followed by a period where mortality rate decreases until the mortality rate is stabilized at a relatively low level (e.g., Stoner and Davis 1994, Furuta et al. 1998, Bettinger and Bettoli 2002, Shimizu et al. 2008, Sudo et al. 2008, Lebata-Ramos et al. 2013, Melnychuk et al. 2014, Long et al. 2018, Poh et al. 2018). Time course studies estimating postrelease mortality rate over time could provide important information about whether prerelease training programs work. When appropriately adjusted for natural size-dependent mortality rates (see Lorenzen 2006 for a model framework), survival curves likely contain relevant information that can reasonably be indirectly associated to behavior and cognition (Fig. 4).

Hypothetically, the initial mortality rate is the immediate site-specific mortality of the stocked animals and can be analyzed to compare effects such as different rearing environments, populations, or species as long as the compared groups are similar in other parameters affecting survival (e.g., body size distribution). The breakpoint (Fig. 4) of the curve can provide information about (1) the proportion of the stocked animals being unsuitable for a life in the wild (if mortality is due to inherited characteristics) or (2) the time it takes for an individual to learn to cope in the natural environment (if mortality is due to reversible behavioral characteristics developed in culture). Performance depends on both inherited and plastic traits, but analyses of the breakpoint for different families, rearing treatments, or behavioral types could help in partitioning the effects of these potential causes. The section of the curve to the right of the breakpoint provides information about mortality processes in the part of the stocked population being most suitable for a life in the wild (Fig. 4). 


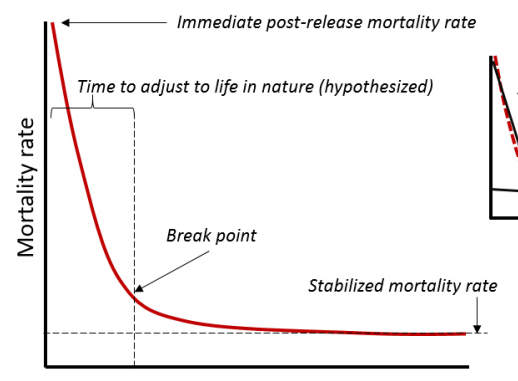

Time after release

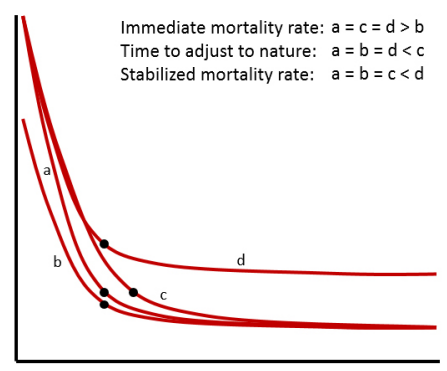

Time after release

Figure 4. Generalized illustration of the postrelease survival time course for hatchery-reared aquatic animals stocked into a natural environment. Mortality rate over the initial postrelease period indicate immediate mortality (likely due to predation, as immediate death of starvation is unlikely). The break point of the curve (estimated by e.g., segmented regression; middle graph) is here hypothesized to measure time to adjust to the wild. The stabilized mortality rate indicates the stocking success. The right graph illustrates four curves $(a-d)$ from hypothetical stocking events differing in postrelease performance in different ways (break points marked with black dots).

Poor poststocking performance is likely multifactorial and depends on species, population origin, body size, ontogenetic stage, rearing environment, and conditions at release. Three phases of establishment of stocked animals have been identified by Henderson (1980): (1) recovery of normal movement and orientation, (2) familiarization with new habitat (which could include identification of predators and shelters), and (3) adoption of a new foraging regime. Problems related to the first phase could partially be due to physiological characteristics caused or developed in the hatchery (e.g., Chittenden et al. 2010, Rosengren et al. 2017) and should be ameliorated as well as possible at the release, using appropriate release methods and sites. The second and third phases are more relevant from the perspective of the development of behavioral and cognitive traits in captivity. Since this paper is discussing these latter issues, some deficiencies of this kind will be presented below (for more exhaustive reviews and examples, see Fig. 2 and references therein).

Comparisons with wild conspecifics provide a benchmark for assessing the general performance of stocked animals (Lorenzen 2006). However, comparing performance between wild and hatchery-reared animals is difficult and usually requires analyses on population level parameters collected from fisheries data. When it comes to improving poststocking performance through hatchery environment interventions, a generally lower performance of hatchery animals should already have been established (otherwise, there is no rationale for improving the hatchery environment). Hence, comparisons could in this context mainly relate to animals from normal rearing vs improved rearing (although, information on wild conspecifics is also informative). Since the groups to be compared are accessible to the researcher prerelease, many detailed parameters of these groups can be measured and accounted for in analyses. Developments in individual identification technology and telemetry (active or passive) allow for collecting very detailed postrelease data relating to, for example, activity and movement patterns, space utilization, growth, and mortality at the level of individuals (e.g., Bettinger and Bettoli 2002, Lennox et al. 2017, Monk et al. 2020, Aspillaga et al. 2021, Lees et al. 2021), as long as potentially negative effects 
of the tagging are accounted for. For instance, smaller individuals can be more affected by tagging than larger individuals (e.g., Vollset et al. 2020).

Neurosensory Development and Cognitive Deficiencies.-The central nervous system of animals is generally plastic, e.g., through environment-associated neuronal activity, neurogenesis, and relative growth of different brain sub-regions (Sandeman and Sandeman 2000, Ayub et al. 2011, Ebbesson and Braithwaite 2012, Bertapelle et al. 2017, Zhang et al. 2020). Since the central neural system affects behavioral expression as well as cognition (e.g., Broglio et al. 2011, Kaas 2017), and its function is influenced by, and optimized for, the environment where an animal lives (Kotrschal et al. 1998), it is reasonable to assume that the rearing environment influences behavior and cognition through effects on the brain. In particular, the typical aquaculture rearing environment is deprived of much of the spatial and temporal variation seen in nature, and it is commonly hypothesized that animals reared in these rearing environments suffer from sensory deprivation, causing development of neural, cognitive, and behavioral traits maladaptive in natural environments (Blaxter 1970, Johnsson et al. 2014). Some evidence points in this direction. For instance, sensory deprivation affects the size of the optic tectum in the brain of poecilid fishes, because of decreased ganglion cell volume (Pflugfelder 1952), which could affect subsequent cognitive abilities and behavior. Lateral line development of fish has also been shown to be negatively affected by captive-rearing, which could affect mechano-sensation and behavior in the wild; whether this is caused by the sensory environment is yet to be determined (Brown et al. 2013b). Possibly, effects could be dependent on life stage, with animals being particularly sensitive during early critical development stages (Browman 1989).

Many studies have investigated relative brain size of individual animals in relation to rearing environment, and has shown a variety of effects, some depending on ontogeny (e.g., Johnsson et al. 2014, Näslund et al. 2017, Zhang et al. 2019). A common underlying assumption when measuring brain or brain subregion size is that larger volumes relative to body size are indicative of improved cognitive capacity (Kotrschal and Kotrschal 2020). Evidence for this is derived from guppies (Poecilia reticulata) selected for larger and smaller relative brain size, but studies relying on plasticallyderived differences are less clear (Kotrschal and Kotrschal 2020). Furthermore, few studies have linked relative brain size to behavioral traits relevant for poststocking performance, but some indicative results have been presented recently. In brain-size selected guppies, a larger brain is beneficial for survival under predation in laboratory mesocosms (Kotrschal et al. 2015). However, effects of plasticity induced changes in brain size remain to be investigated. In another guppy study, Burns and Rodd (2008) found that smaller forebrains tended to be associated to hastier decision-making. Furthermore, Salvanes et al. (2013) showed that more complex rearing environments can lead to both promoted neuroplasticity at the molecular level and increased spatial learning ability in Atlantic salmon. Hence, changes in the brain caused by the rearing environment remain a viable hypothesis for, at least some, behavioral deficiencies (Ebbesson and Braithwaite 2012, Jonsson and Jonsson 2014).

Cognitive traits, such as learning and memory capacity, are often hypothesized to be poorly developed in barren-reared hatchery animals as compared to wild conspecifics (Ebbesson and Braithwaite 2012). Even though the assumption is common, there is surprisingly few studies demonstrating this, possibly because it is difficult 
to control for effects of previous experience when using wild individuals. However, several studies show cognitive differences between hatchery animals reared in different environments (Brockmark et al. 2010, Strand et al. 2010, Salvanes et al. 2013, Cogliati et al. 2019), indicating that the rearing environment plays a part in cognition, at least in the short-term. Makino et al. (2015) showed that learning ability of cultured striped knifejaws (Oplegnathus fasciatus) was inferior to wild conspecifics. In contrast, cultured brown trout can be more successful than wild conspecifics in foraging learning tasks; however, this effect could also stem from stronger feeding motivation in the cultured fish, rather than cognitive superiority (Adriaenssens and Johnsson 2011). Some other studies, for example on fish and snails, show no indications of differences between wild and cultured individuals (Orr et al. 2008, Benhaïm et al. 2013), but effects may depend on which specific cognitive traits are investigated. Cognitive traits are typically only possible to investigate in laboratory environments and there is yet little knowledge about how individual cognitive traits affect performance in nature for animals in general (Cauchoix et al. 2020).

Overall, a barren, predator-free environment where food is continuously supplied ad libitum (i.e., the typical aquaculture environment) might not stimulate the formation of neural and cognitive traits needed for appropriate behavioral capacities and flexibility in the wild, leading to a phenotype maladapted for the natural environment (see references in Fig. 1). However, more studies are needed to demonstrate whether and how cognition differ between wild and cultured individuals, as well as whether differences in brain size, neural plasticity and general cognition have any major effects on performance in the wild.

Deficient Antipredation Behavior.-The initial behavioral issue for stocked animals is suboptimal antipredation behaviors, often acting from the instant the animals are released. Antipredation behavior is important for survival in nature, but also potentially costly, as time spent not feeding (or reproducing) could decrease overall fitness (Brown 2003). Hence, it is likely that antipredation behavior is plastic and influenced by recent experiences through learning, so that animals can adjust their time budget in relation to perceived threat levels (Brown 2003; Kelley and Magurran 2003). Relaxation of the need to express antipredatory responses could thereby be one reason why animals reared in predator-free environments show low expression of these reactions when needed.

Many aquatic species have a reflex-like fright response to visual cues possibly representing a threat (Rowland 1999) and to chemical compounds ("alarm cues") released from injured conspecifics (Vokoun and Noltie 2002, Wishingrad et al. 2014). In some species, chemical cues from natural predators can be innately recognized (Berejikian et al. 2003), but it may depend on the predator species (Vilhunen and Hirvonen 2003, Gall and Mathis 2010), ontogenetic stage (e.g., Hawkins et al. 2008), and in several studies no innate recognition is indicated (e.g., Wisenden et al. 2004, Martin 2014).

While some reactions are innate (Kelley and Magurran 2003), decades of studies have shown that antipredation behaviors are partially learned, and hatchery-reared animals often differ from wild conspecifics in their reactions to threatening situations (e.g., Kanidyev et al. 1970, Stoner 1994, Olla et al. 1998, Einum and Fleming 2001). Already a century ago researchers described how hatchery reared fish behave as if they are relatively unaware of risks (e.g., Robertson 1919, Sörensen 1919). Lack of 
experience of predation will thereby likely lead to a deficient behavioral repertoire for coping with predators (e.g., Malavasi et al. 2004, Karplus et al. 2006, Gristina et al. 2011), leading to substantial losses before the stocked animals learn to respond appropriately. After releasing 50,000 juvenile hatchery-reared olive flounders (Paralichthys olivaceus), Sudo et al. (2008) found a mortality of $68 \%-83 \%$ over the first week in the wild, mainly caused by crabs and predatory fish in the release area. Furuta et al. (1998) found that almost half of their stocked juvenile olive flounder disappeared after only a day in the wild, and predation by fishes was verified through stomach content analyses. Ebner and Thiem (2009) showed that while 95\% of wild radio-tagged trout cod (Maccullochella macquariensis) were found alive 13 mo postrelease, the survival of hatchery-reared conspecifics was only $9 \%$. Evidence from a related study suggested cormorant predation as a primary candidate for the high mortality (Ebner et al. 2007). Losses of hatchery-reared fish and invertebrates are, at least partly, hypothesized to be caused by behavioral antipredation deficiencies such as high rate of near-surface or otherwise conspicuous foraging (Furuta et al. 1998, Kellison et al. 2000), improper activity and habitat choice (Bettinger and Bettoli 2002, Oliver et al. 2006, Thompson et al. 2016), reduced shelter-seeking or burying behavior (Stoner and Davis 1994, Álvarez and Nicieza 2003, Young et al. 2008, Martin 2014, Hair et al. 2020), improper shoaling (Malavasi et al. 2004), reduced reactivity and escape behavior (Schiel and Welden 1987, Brokordt et al. 2006), and generally reduced risk aversion (Yamamoto and Reinhardt 2003, Kelley et al. 2005). Obviously, species-specific antipredation strategies need to be considered when designing possible ameliorating rearing or training programs; knowledge about the autecology of the subject species is of high importance.

Deficient Foraging Behavior.-Deficient foraging behavior in natural environments is another potential cause explaining mortality rates but probably later in the postrelease time course, given that lethal starvation is unlikely to occur immediately after release (Olla et al. 1998, Einum and Fleming 2001, Tomiyama et al. 2011). Some aspects of foraging behaviors are innate and hatchery-reared predators typically manage to feed on live prey, although often with lower efficiency than wild conspecifics (e.g., Paszkowski and Olla 1985, Fjellheim et al. 1995, Ellis et al. 2002, Seebacher et al. 2010). Learning rates are typically rapid when repeatedly exposed to live prey (e.g., Ware 1971, Paszkowski and Olla 1985, Reiriz et al. 1998, Cámara-Ruiz et al. 2019b), but learning rates can differ for different prey types (Vinyard et al. 1982, Stradmeyer and Thorpe 1987) and across ontogenetic stages (Donadelli et al. 2015). Furthermore, the selection of prey may not be optimal (Reiriz et al. 1998). Given that food is continuously available in the wild, postrelease learning rates could possibly be even faster than indicated in laboratory experiments, which typically implement only a few feeding trials per day. Nevertheless, foraging in nature often seems inefficient. Stomach content analyses have indicated that hatchery fish without live food experience are inept foragers for several weeks to months postrelease (Sosiak et al. 1979, Fujii and Noguchi 1993, Skov et al. 2011, Tomiyama et al. 2011). Possibly, naive hatchery fish do not only need to learn to forage on natural food, but also need to learn where and when to forage while simultaneously learning other necessary life-skills. Such divided attention could lead to inefficient learning (Warburton and Hughes 2011), and consequently poor foraging performance. 
Foraging deficiencies can be expressed as improper selection of foraging areas (Sosiak et al. 1979, Kellison et al. 2000), low ability to find and identify prey (Tomiyama et al. 2011), improper prey selection (including low-quality and inedible items; Lord 1934, Sosiak et al. 1979, Nordeide and Salvanes 1991, Ellis et al. 2002, Orlov et al. 2006), and low ability to capture and handle identified prey (Sundström and Johnsson 2001, Wintzer and Motta 2005). Even if several factors could play parts in the problem picture, foraging deficiencies are often hypothesized to be linked to the lack of recent experience of natural live food. Food items encountered in the wild are more or less novel to the released animal, which tends to decrease efficiency of consumption (Sundström and Johnsson 2001). A study on trumpeter whiting (Sillago maculata) showed that duration of exposure to a specific food type can affect both the senses used to locate food (e.g., olfactory vs visual detection) and the efficiency with which a specific dietary item is detected (Norris 2004).

Although immediate poststocking starvation mortality is not expected directly from improper foraging skills, there may be indirect effects caused by predation. Recently stocked individuals could for instance be weakened by low recent energy intake, and hungry individuals may also be risk-prone when searching for food, leading to elevated exposure to predators (Milinski 1993). Improper foraging area selection may also feed into increased predation risk. For instance, several studies of cultured fish with a natural benthic foraging mode have indicated that their food search is directed to the open water or surface instead of the benthos, due to being accustomed to surface food delivery in the rearing facilities (Kellison et al. 2000, Takahashi et al. 2013, Krepski and Czerniawski 2019). Furthermore, even if foraging ability is not affected, a deficient competitive ability (Metcalfe et al. 2003) will lead to similar resource acquisition deficiencies.

Other Behavioral Deficiencies.-Other possible behavioral deficiencies in cultured animals include migration and movement behaviors (Einum and Fleming 2001, Bolland et al. 2008, Ebner and Thiem 2009), habitat use (Mesa 1991, Teixeira et al. 2006, Bolland et al. 2008), sociality and aggression (Mesa 1991, Deverill et al. 1999, Berejikian et al. 2001), and reproductive behaviors (Jonsson et al. 1990, Einum and Fleming 2001, Kelley et al. 2005, Slavík and Horký 2021). While investigated in several studies (mainly in fish, particularly salmonids), these behaviors have generally received less attention in research regarding poststocking performance, perhaps because they are less relevant for immediate postrelease performance than antipredation and foraging behaviors.

"SтоскавіLIтY."-Given that some species can be stocked successfully after being reared in hatcheries, while others seemingly cannot, one can hypothesize that species likely differ in their "stockability". A highly "stockable" animal could have innate characteristics (e.g., ecological niche, life-history, or behavior) that are plastically insensitive to artificial environments. For instance, development of traits important for performance in the wild may not be plastically responsive to environmental conditions in aquaculture. Alternatively, the species' reaction norm to hatchery conditions may still produce phenotypes viable in nature. The argument follows a similar reasoning as the one made about certain species being more invasive when introduced into new geographic areas (e.g., Chapple et al. 2012; also, cf. "capacity for feralization"; Lorenzen et al. 2012). The question of which species are less sensitive to being 
cultured (most suitable for stocking) can be important for allocation of resources for hatchery rearing of different species. General predictions could potentially be gained through comparative approaches, where species with different ecological, life-history, and physiological traits are compared in terms of phenotypic responses to artificial rearing and postrelease performance.

In addition to relating to different species, the stockability concept could also be applied on the population-level variation in behavioral characteristics among individuals (i.e., "personality" traits; Briffa and Weiss 2010). Some behavioral phenotypes within a population may be less sensitive to artificial culture conditions and may therefore have higher success postrelease (Mittelbach et al. 2014); a similar argument has been made for individuals with certain behavioral traits being more successful invading when introduced in novel environments (Chapple et al. 2012). Thus, even if there is a large variation in, for example, behavior among the stocked individuals, the final survivors may constitute a biased portion of the initial population, not due to being superior in nature, but because they are less influenced by the rearing. Hence, the survivors may not represent a natural population in terms of behavioral trait distribution. Whether this happens or has effects on natural ecosystems requires more investigation.

\section{Improving Postrelease Performance: Animal Training and Experience}

Solving the problem of poor postrelease performance of stocked animals could be approached from different angles. Firstly, we can provide a better stocking situation when the animals are released (in situ strategies). Simpler in situ solutions involve releasing the animals at appropriate sites in an appropriate manner (Keil 1935) and at a suitable bodily state (Lü et al. 2018). Favorable conditions for immediate releasesurvival can relate to a certain season, areas where predation is low, or areas where food abundance is high (e.g., Tanaka et al. 2006, Taylor et al. 2009, Hervas et al. 2010, Lü et al. 2018). In situ acclimation (soft release) in cages or shelter structures during the initial phase of the release is another method that could be applied (e.g., Keil 1935, Brennan et al. 2006, Lebata-Ramos et al. 2013, Tetzlaff et al. 2019). These strategies, however, will not be discussed here, as they do not aim to counter potential behavioral issues developed in the rearing environment causing poor performance over an extended period.

Secondly, we can potentially provide a better rearing environment and prepare individuals for a life in the wild (ex situ strategies). This typically involves "training" interventions such as sensory stimulation, prerelease conditioning, and exposure to natural features within the hatchery environment. Kleiman (1989) presented six main areas to consider when developing prerelease training programs for mammals: predator avoidance, acquisition and processing of food, locomotion through complex terrain, orientation and navigation in a complex environment, finding shelter or constructing nests, and proper interaction with conspecifics. The same areas of consideration are relevant to aquatic animals within stocking programs. Four general approaches aimed to address these are reviewed below: (1) antipredation training, (2) foraging training, (3) exposure to structural complexity and substrates (relating to locomotion, orientation, navigation, and sheltering), and (4) reduced tank density (e.g., relating to the social environment). 
While not part of the scope of this review, it is worth mentioning that other methods than the ones covered here have been applied to improve the behavior or the physiological traits facilitating certain behaviors. Physical exercise through increased flow during rearing can influence traits relevant for postrelease performance such as stamina, behavior, and cognition (see e.g., Davison 1997, Kieffer 2010, Gomez-Pinilla and Hillman 2013, Franssen et al. 2021). Reduced or variable food supply can affect, for example, metabolic traits, postrelease growth, and migration willingness (e.g., Garlock et al. 2014, Persson et al. 2018). Furthermore, the time spent in the artificial rearing environment may be a factor of consideration. If behavioral and cognitive traits are progressively altered away from wild-like phenotypes, then a shorter time in captivity could be better (but see Crossman et al. 2011). However, this may have to be weighed against natural age- and size-dependent mortality rates in nature. There may also be training strategies that could improve poststocking survival without necessarily aiming for a wild-like behavior. For instance, training cultured animals to avoid "unnatural" mortality related to capture by humans (e.g., avoiding taking anglers' baits or entering traps) could possibly be considered within an antipredation context, e.g., through associative learning or social learning protocols (Lovén Wallerius et al. 2019, 2020). For a species of conservation concern, it is preferable that the released individuals are not captured after release.

It should be noted that not all operating hatcheries are willing to undertake the types of interventions discussed here (Hutchison et al. 2012a), and some interventions come with possible negative side effects, as noted below. The following sections provide critical summaries of experiments. In-depth discussions about experimental details are not included, but more detailed summaries of all reviewed papers are found as supplementary material in the figshare data repository (see Online Supplementary Material). Focus is primarily placed on species relevant for stocking.

Antipredation Training.-Immediate postrelease predation is a major issue which has attracted substantial research efforts, including predator recognition and antipredation training. Experimental protocols typically follow two different approaches: (1) classical conditioning and (2) direct exposure to predation cues. The distinction between these categories is not clear, since direct exposure often has strong elements of associative learning (e.g., being chased or seeing other individuals killed by a predator). However, when predators are simply introduced as training stimuli, without direct control over the release of different stimuli (US/CS), the experiment is classified as an 'exposure' experiment, rather than a 'conditioning' experiment. Note that exposure of captive animals to predators is prohibited by animal protection laws in many countries.

Conditioning Experiments.-Most studies implementing conditioning use chemical alarm cues from injured conspecifics as the US, which is associated to a predator cue as the CS. The aim is to condition the animal to recognize predation risk in the wild at an early stage in the predation sequence (i.e., before an attack) and adapt its behavior accordingly.

Several studies have conditioned alarm cues to chemical predator cues ("predator odor"), to reduce postrelease risk-taking in the presence of predators, before the actual encounter with the predator occurs. Laboratory results from a variety of species indicate that improved antipredation reactions can be obtained quickly, sometimes 
already after a single conditioning trial (Brown and Smith 1998, Mirza and Chivers 2000, Berejikian et al. 2003, Wisenden et al. 2004, Crane and Mathis 2011, Olson et al. 2012, Archer and Crowl 2014, Sloychuk et al. 2016). Effects of single session conditioning to predator odor, however, may affect only some, but not all aspects of antipredation behaviors (Berejikian et al. 1999). In Arctic charr (Salvelinus alpinus), a single conditioning session led to improved antipredation responses, but repeated conditioning (up to four sessions) increased the response further, indicating no habituation effects over these sessions. In contrast, effects of conditioning disappeared already after the second session in chinook salmon (Oncorhynchus tshawytscha; Berejikian et al. 2003), indicating that it may be hard to generalize effects across species, even if they belong to the same family (both charr and salmon are salmonids). The retention of the conditioned response after a single session has been investigated in a few studies, with varying results. June suckers (Chasmistes liorus) retain the response for $<10 \mathrm{~d}$ (Archer and Crowl 2014), while brook charr (Salvelinus fontinalis) retain it for $\geq 10 \mathrm{~d}$ (Mirza and Chivers 2000). Rainbow trout (Oncorhynchus mykiss) were shown to retain a significant, albeit weakened, response after $21 \mathrm{~d}$ in Brown and Smith (1998), but no detectable responses were seen after $9 \mathrm{~d}$ in Berejikian et al. (1999). These rainbow trout experiments used similar exposure time during conditioning (10 vs $8 \mathrm{~min}$ ) but tested different life stages (fish were younger in the latter study) which potentially explains the different results. Sloychuk et al. (2016) showed ontogenetic effects in lake sturgeon (Acipenser fulvescens), where young, but not older, juveniles could be conditioned to pike odor. Several other studies also suggest ontogenetic shifts in responses to chemical alarm substances in aquatic organisms (e.g., Brown et al. 2001, Harvey and Brown 2004). Ontogenetic effects may be speciesspecific, but the indications of their existence suggest that one must test the stage at which the fish are released. More standardized experiments comparing number of conditioning trials and retention time are often needed for a fuller understanding of how to optimize conditioning to predator odor for a given species.

A few studies have tested postrelease performance after predator odor conditioning, with less than satisfying results. Hawkins et al. (2007) found no effects of a two-session conditioning to pike odor on migration survival in Atlantic salmon, and Berejikian et al. (1999) found no improved survival in chinook salmon over 2.5 mo in a natural stream, after conditioning to cutthroat trout (O. clarkii) odor. In the latter study, however, conditioning mitigated the reduced survival seen in fry with experience of a complex environment in the hatchery, as complex-reared fry otherwise sought to hide in areas where the predatory trout also hide.

Some studies condition visual or physical predator stimuli to alarm cues. Olla and Davis (1989) presented juvenile coho salmon (Oncorhynchus kisutch) with predators behind screens together with alarm cues and found an improved survival performance in laboratory predation trials $5 \mathrm{~d}$ posttraining; two 15-min conditioning sessions were found to be better than a single one. In one of few invertebrate studies, common whelks (Buccinum undatum) were conditioned using alarm cues (US) and contact with predatory starfish (CS), a treatment which increased the antipredation response (Rochette et al. 1998).

A few studies have used electric shocks or net-capture as US, which are both unnatural stimuli but induce strong fright reactions without previous experience. Electric shocks were used in attempts to condition fright reactions to bird models in brook charr, but without detectable survival benefits 10-12 wks poststocking (Fraser 
1974). However, similar approaches using fish models as NS/CS indicated successful conditioning and improved postrelease performance in chinook and chum salmon (Oncorhynchus keta; Thompson 1966, Kanayama 1968). Net-capture as US was used by Mesquita and Young (2007), who showed that it could be used to condition a longlasting (up to at least $75 \mathrm{~d}$ ) antipredation-like CR toward a predator fish model within 12 conditioning sessions in Nile tilapia (Oreochromis niloticus).

Most studies using conditioning assume that the salience of US and associability of the CS are very strong, given the typically low number of conditioning trials used (often only one). It is worth noting that other US-CS combinations (like a flashing light bulb being associated with food), can require over 30 associations for the formation of a reliable associative response (Tarrant 1964). High salience may indeed be true for an ecologically relevant US like alarm cues, but just finding a significant difference between conditioned and nonconditioned individuals is no indication that the response level reached will improve the survival in nature, since the detected difference may not be large enough. If possible, researchers could try to identify how strong an antipredation response needs to be to reduce mortality risk in a natural setting to an acceptable level, and then investigate how many conditioning trials are needed to reach this response level.

Direct Exposure Experiments.-In direct exposure experiments, predators are simply added to the rearing environment to impose predator experience on the subjects (as noted above, this may not be a legally acceptable solution, depending on national laws). Exposure training can be conducted using either direct predator-prey contact or no-contact predator exposure. In the first case, predators can feed freely on the subjects; in the second, predators constitute visual stimuli and are confined in a separate area, typically feeding on sacrificial conspecifics to the subjects. Direct contact exposure has been shown to be more efficient in changing antipredation behaviors than no-contact exposure in fish and crabs (Järvi and Uglem 1993, Arai et al. 2007, Daly et al. 2012). No-contact exposure can also be applied using only chemical predator cues (i.e., without conditioning to e.g., alarm cues, assuming an innate response). This latter application is hypothesized to prime the animals to the presence of predators prior to release, hopefully making them less risk-prone postrelease; learning would not be the key aim here, as the response to chemical predator cues needs to be innate.

Studies on direct predator exposure as a life-skills training method are highly variable in their results. Some experiments show no effects on antipredation behaviors after repeated exposures (Beck and Rooker 2012). Others show changed antipredation behavior but without detected or conceivable positive effects for survival in nature (Wahl et al. 2012, Petersson et al. 2015). Maladaptive diurnal activity in captive rock lobsters (Jasus edwardsii) is ameliorated when exposed to diurnal predators in the captive environment; however, the adaptation to nocturnality is rapid after release, making the efficiency of the training effort questionable (Oliver et al. 2006). Laboratory studies on red abalone (Haliotis rufescens) also indicate quick acclimation to novel environmental factors, such as predation risk (Schiel and Welden 1987). Other experiments demonstrate improved survival, either in lab studies (Berejikian 1995, Mueller et al. 2007) or postrelease monitoring (D'Anna et al. 2012), or at least indicate improved behavioral responses to predators (Fujikawa and Sasaki 2001, Hossain et al. 2002). Repeated in-tank net chasing of subject animals, as a form of 
(predator-free) direct exposure training has been shown to lead to both changed behaviors and reduced predation mortality (Takahashi et al. 2013, Takahashi and Masuda 2018), indicating that the predator recognition part may be over-emphasized in predation-training programs. Possibly, a change in general risk-awareness and risk-aversion could be enough for improved postrelease survival.

A few projects have exposed their subject animals to predation by stocking them into natural or seminatural environments during parts of the rearing period (i.e., prior to release in the target stocking area). A study on eastern king prawns (Penaeus plebejus) showed no improved survival rates after spending part of the rearing period in a closed natural coastal lake (Ochwada-Doyle et al. 2010). Sockeye salmon (Oncorhynchus nerka) fry instead increased their survival with increased exposure to predators in an experimental stream, mediated through increased shoaling tendency (Ginetz and Larkin 1976). Similarly, Florida bass (Micropterus floridanus) showed improved poststocking survival after a 10-d exposure to predators in an earthen pond (Trippel et al. 2018). From a management perspective, these studies are interesting as they can be relatively easy to implement, as long as there is access to (semi-)natural ponds from which the animals can be easily retrieved. However, many uncontrolled features (e.g., presence of natural food, environmental complexity, unknown levels of predation exposure, etc.) may influence later performance, so these studies are less useful when trying to pin-point what specific factors affect postrelease performance.

No-contact visual/chemical predator exposure experiments are also variable in their results, with some studies showing modified antipredation behaviors and improved survival in laboratory predation trials, in both fish and gastropods (Kellison et al. 2000, Delgado et al. 2002). As with direct exposure, using net-chasing seems to work to improve antipredation behaviors also from a no-contact setting; even exposure to video recordings may have an effect (Takahashi et al. 2015). Studies using only chemical predator cues as the training stimuli are often found inefficient (Brokordt et al. 2011, Kopack et al. 2016, Cámara-Ruiz et al. 2019a), effects that hypothetically may depend on predator odor not being innately recognized by some species.

A few experiments are by design intermediate between conditioning and exposure studies. For instance, subject animals can be exposed to predators behind screens for several days, with intermittent addition of chemical alarm cues. Hutchison et al. (2012b) found that Murray cod (Maccullochella peelii) survived better in the wild after such training (3-d predator exposure, with alarm cues added twice daily), while silver perch (Bidyanus bidyanus) showed no such improvement. When applying a similar protocol to yellowfin bream (Acanthopagrus australis; 6-d of predator exposure, with seabream flesh added to predators once daily), only subtle and inconsistent responses to predators were detected a day posttraining (Rae et al. 2020). Similarly, common whelks exposed to predatory starfish odor and alarm cues, with intermittent exposure to live predators over 2 mo, did not show notably improved antipredation responsiveness (Justome et al. 1998). Chilean scallops (Argopecten purpuratus), however, seem to adapt an enhanced antipredation behavior in a similar setting (7-d alarm cue exposure, with direct starfish contact 3 times daily; Brokordt et al. 2011). One potential problem with this type of exposure is that the live predator cue may become less associable with the alarm cues with time, given that the predators are present all the time, while alarm cues are intermittent. That is, there can be uncertainty about whether predator presence is associated with the occurrence of alarm cues, from the prey's perspective. Continuous release of dietary-origin alarm cues 
(e.g., from predator feces), may mitigate this problem (Justome et al. 1998, Rae et al. 2020), but it has not been clearly demonstrated and it could also possibly lead to habituation.

Ontogenetic effects on antipredation learning are sometimes detected also in the direct exposure studies. In Chilean scallops, older individuals show higher responsiveness (Brokordt et al. 2011), and red seabream appear to become more variable in their response when older (Fujikawa and Sasaki 2001). Likely, there are also major species-specific effects on responsiveness and learning ability in general, depending on both subject and predator species (Daly et al. 2012). Both areas deserve more research attention. Retention of the learned responses, which may wane quickly (Arai et al. 2007), and exposure time needed for long-term retention are other subjects requiring more research.

Social Transfer Studies. - In one study using direct-contact training for coho salmon, experienced fish had similar survival (75\%) as naïve ones (71\%) when tested together in subsequent laboratory predation trials (Patten 1977). However, when naïve fish were tested alone, their survival was much lower (46\%); it was interpreted that rapid social transfer of antipredation behaviors occurred between experienced and naïve fish during the predation trials when both groups were trialed together. This finding opens the possibility of using previously trained animals as stimuli in antipredation training programs, which could reduce the amount of effort needed to train animals. More recently, Vilhunen et al. (2005) trained some Arctic charr using classical conditioning (US: alarm cue; CS: contact with live predator), and then released these fish into tanks with naïve conspecifics. Adding predator cues to the new tank induced antipredation behaviors in the conditioned fish, which were socially transferred to the naïve fish, but only in groups with a smaller proportion of conditioned individuals. The authors hypothesize that experienced fish in naïvemajority groups may have enhanced their reactions due to the inadequate response (lack of protective shoaling) of the naïve fish to the predator cue, but behavior was not directly observed in social learning trials and the hypothesis remains to be tested (Vilhunen 2006).

Foraging Training.--The main hypothesis behind inefficient live-food foraging in cultured animals relates to inexperience of natural food. Recognizing that some innate ability to forage on natural food typically exists, many of the studies investigating whether foraging can be improved prerelease approach the problem through simple exposure to natural prey. Most food-training experiments on fish have provided encouraging results, indicating quick improvements in foraging proficiency (Warburton and Hughes 2011). Studies on invertebrates are largely lacking, which could be an effect of foraging not being generally considered a problem for invertebrates, many of which are often food generalists or using simpler modes of foraging (e.g., scavenging, grazing, or filtration; Daly et al. 2020).

Most studies focus on teaching the animals what and how to feed, but a few also aim to create experience of where to feed. In general, further studies on relative efficiency of different approaches, learning time courses, and estimation of what level of learning is "good enough" in terms of improved postrelease performance are generally needed for foraging-training schemes. 
Direct Exposure Studies.-Experiments often apply foraging-training by simply supplying live food directly to the rearing tanks. This exposure-training method, which is not strictly a conditioning procedure since only one stimulus is used, resembles sequential priming in cognition experiments, where the aim is to increase the ability to find a certain prey type that have recently been experienced during training. A study on common cuttlefish (Sepia officinalis) even indicates that preembryonic visual exposure to certain food types (in this case crabs) can modify food preferences (Darmaillacq et al. 2008). Curiously, exposure to prey odors, instead of visual cues, reversed the preference (Guibé et al. 2010).

Most published studies show positive effects of live food exposure on later live prey foraging, although a few exceptions do exist (Massee et al. 2007). Some results are published after showing improved foraging ability on live prey in a laboratory setting (Vinyard et al. 1982, Colgan et al. 1986, Maynard et al. 1996, Ellis et al. 2002, Seebacher et al. 2010, Donadelli et al. 2015, Ciszewski et al. 2020). Such results provide preliminary evidence for training being possible but foraging in a simple laboratory environment may not reflect performance in a more complex natural environment (Jackson et al. 2015). Furthermore, a laboratory study on Atlantic salmon suggests that enhanced foraging is improved slightly by experience, but the effect was increased when combining live food with rearing in complex environments (Brown et al. 2003a). The benefit of laboratory tests is the possibility to obtain detailed results from highly controlled situations, which are much harder to obtain in natural underwater environments. For instance, the finding that prey preference of initially naïve individuals changes rapidly with experience, conforming with predictions based on optimal foraging theory (Reiriz et al. 1998), would be difficult to produce with the same level of detail in a field study as compared to a laboratory study. Nevertheless, to get a good indication of whether postrelease performance is influenced by foraging-training, complimentary release-recapture experiments are needed, as a laboratory environment cannot solely provide the evidence required for a robust ecologically relevant conclusion (Johnsson and Näslund 2018).

A series of studies on stocked salmonid fry, fed live food prior to release, have repeatedly shown that postrelease growth and survival rates are higher in individuals with live-food experience (Czerniawski et al. 2010, 2011, 2015), but also that the type of prey used in training can influence the results (Czerniawski et al. 2011). Follow-up laboratory studies suggest that effects are due to improved foraging per se (Ciszewski et al. 2020). Studies on pikes (Esox spp.) show improved survival in the wild after prerelease live food exposure, without indications of improved foraging ability or altered habitat choice or antipredator behavior (Szendrey and Wahl 1995). The power to detect small differences can be low in field studies, but the authors in the latter study noted that coloration of the fish seemed influenced by the treatment, which may have increased survival rates. Walleye (Sander vitreus) trained with live prey and stocked into small predator-free ponds showed no signifficant differences in survival and growth after either 15 or $30 \mathrm{~d}$ compared to naïve walleye, possibly reflecting the rapid learning of foraging skills indicated in lab trials (within 5 trial days; Wahl et al. 1995). In a similar pond-stocking experiment, prey-experienced largemouth bass (Micropterus salmoides) were found to grow faster than prey-naïve conspecifics, but survival did not differ between these groups (Diana et al. 2018). Costas et al. (2013) found no survival benefit of feeding Atlantic salmon juveniles with invertebrates for 2 wks prerelease in a 3 -wk release experiment in a screened-off river section. This 
result contrasts with findings by Czerniawski et al. (2011), but local release conditions, ontogenetic stage, or another unidentified factor may have caused differences in effects. In general, results from field trials differ among species and/or experiments. To generalize knowledge and pinpoint what causes the differences, different species and experimental protocols may need to be compared within single research projects to ascertain context being directly comparable.

Social Learning Studies.-A few studies have applied foraging training through social learning (Suboski and Templeton 1989, Brown and Laland 2001), where naïve fish observe trained fish foraging, the main benefit being that only a few fish need to be extensively trained and that the number of prey used during training can be substantially reduced. Studies on Atlantic salmon showed that this approach may work for teaching naïve fish to forage both on live food (Brown and Laland 2002) and to forage closer to the bottom (Brown et al. 2003b). However, none of these experiments were scaled-up to handle the numbers of fish produced under normal stock-fish culture programs. Takahashi et al. (2015) tried both live demonstrators and playback of video-recorded fish to train red seabream (Pagrus major). In this case, the fish learned to forage on live prey rapidly, but without any effect of having observed conspecifics forage being demonstrated. For evaluation of whether a social-learning protocol is more cost effective, demonstration of effectiveness in larger scale rearing systems is required. Notably, the efficiency of foraging training in groups, where social transfer can increase the steepness of the learning curve, can potentially be influenced by the group constitution. Studies show that individual foraging performance can be conditional on which behavioral types are included in the group (Jolles et al. 2017).

Prey Capture Kinematics.-One of the mechanisms behind improper foraging in fish is hypothesized to be inadequate prey capture kinematics of the mouth parts. Pellet-reared Florida bass have been shown to initially use a different capture technique than wild bass, with a higher degree of suction and lower prey capture success, but these fish learn how to feed appropriately within five prey exposure trials (Wintzer and Motta 2005). Similar results, with initially differing prey-capture kinematics being quickly improved in hatchery individuals are seen in common snook (Centropomus undecimalis; Caldentey et al. 2021). These studies provide direct evidence of fish learning the mechanics of feeding on natural prey very rapidly.

Associative Priming Studies.-Some food-training studies apply more complex training schemes with additional aims such as associative priming, where natural food becomes associated with a particular substrate (Cámara-Ruiz et al. 2019b) or a specific location in the water column (typically the bottom; Krepski and Czerniawski 2019, Takahashi et al. 2013). The aim of these studies is to make the animals feed in the proper areas postrelease. Cámara-Ruiz et al. (2019b) not only improved in-substrate foraging behavior of Atlantic sturgeon (Acipenser oxyrinchus), but also demonstrated a possible neurophysiological mechanism behind it as they found increased neurogenesis in the brain, associated with learning and memory in the fish. Krepski and Czerniawski (2019) released bottom-foraging trained brown trout (Salmo trutta) into natural streams and found that bottom-fed individuals had higher growth rates in shallow streams, but interestingly not in deeper streams. This result illustrates the 
complexity of the problem of assessing lab-derived results, as the postrelease effects also depend on the release environment.

Exposure to Complex Environments (Environmental Enrichment).Increased environmental complexity, in the form of added physical structures or substrates to rearing tanks (commonly referred to as "environmental enrichment"), is typically aimed at providing captive animals either a more cognitively stimulating environment, or to provide them with experience of a more heterogenous "habitat" during upbringing (Johnsson et al. 2014, Näslund and Johnsson 2016). Enrichment is also often applied to reduce distress and its negative consequences on performance and welfare (Näslund and Johnsson 2016).

Bottom-substrate.-For bottom-dwelling animals, natural substrates (e.g., mud, sand, gravel, or shell hash) can be important for learning or improving upon natural behaviors such as hiding, foraging, and adaptive color change. Exposure to natural bottom substrate in the hatchery can quickly improve natural burying behaviors (often within a few days) in several crustacean, cephalopod, and flatfish species, likely providing survival benefits at release (Wickins and Barry 1996, Ellis et al. 1997, Fairchild and Howell 2004, Poirier et al. 2004, Parkes et al. 2011). Quick learning responses, however, also indicate that this may be achieved soon after release in naive animals. Hence, survival effects may be expected mainly very soon after release, during the immediate postrelease mortality phase (see Fig. 4). Some species [e.g., European flounder (Platichthys flesus) and turbot (Scophthalmus maximus)] seem to bury well even without experience of substrate (Kristensen et al. 2014). Substrate exposure can also alter other behaviors, such as exploration or bottom-association in cephalopods (Yasumuro and Ikeda 2011, 2016).

Adaptive coloration (i.e., background-matching) can also be substantially improved by exposure to substrate in crabs, cuttlefish, and flatfish (Davis et al. 2005, Parkes et al. 2011, Yasumuro and Ikeda 2011). In contrast to hiding behaviors, achieving an appropriate color-matching response can take a long time. For flatfish, some aspects of coloration (like chroma and hue adaptation) can take several months to achieve (Ellis et al. 1997, Fairchild and Howell 2004).

Physical Structures and Shelters.-Three-dimensional complexity in the form of added structures such as stones, pipes, bricks, artificial plant-like structures, or natural plants are often assumed to simulate a more natural environment. A more complex environment than the standard barren hatchery tank may promote both cognition and behavioral flexibility, as such environments allow animals to cope with stressors and changes in their environment in a varied way (Niemelä et al. 2013). In environments with too high complexity or variability, development of necessary cognitive capacity and behavioral flexibility may be too costly, leading to stereotyped behavioral coping (Niemelä et al. 2013); however, compared to natural environmental complexity, most physical enrichments are probably still at the lower end of complexity. Thus, adding in-tank structures could hypothetically provide cognitive stimulation, lead to higher behavioral flexibility, induce stronger sheltering behaviors, or affect behaviors in other ways (Braithwaite and Salvanes 2005).

Improved sensory stimulation and cognition are commonly expected effects, particularly in fish where positive enrichment-effects on brain size and plasticity have 
been demonstrated experimentally (e.g., Kihslinger and Nevitt 2006, Salvanes et al. 2013). Improved cognitive ability could likely affect many behaviors dependent on information processing and retention (e.g., foraging, predator avoidance, or navigation in complex environments). Atlantic cod (Gadus morhua) from complex rearing environments indeed show higher ability to learn foraging on novel prey from tutor fish (Strand et al. 2010). In addition, complex-reared striped knifejaws show improved learning ability in a classical conditioning context, but only during a certain ontogenetic stage (50-80 d post-hatch), indicating a possible critical period for effects to be expressed in this species (Makino et al. 2015). Positive enrichment effects on learning and memory have also been detected in common cuttlefish (Sepia officinalis), with effects being dependent on exposure-time (Dickel et al. 2000). Increased spatial learning in maze trials have been detected in rainbow trout, with effects increasing along with increased enrichment-exposure time (Ahlbeck-Bergendahl et al. 2016). Positive effects on spatial learning have also been seen in Atlantic salmon (Salvanes et al. 2013), but not in brown trout or chinook salmon (Brockmark et al. 2010, Cogliati et al. 2019). This variation in effects seen in salmonids puts the generality of effects of enrichment into question, and it would be useful to further investigate what causes these differences (species-specificity, types of enrichment structures, experimental design, or other factors).

Improved sheltering behavior is another expected effect of physical enrichment. Higher sheltering tendency may be adaptive soon after release in the presence of natural predators and has been shown to increase after exposure to structurallyenriched rearing environments in both fish (Salvanes and Braithwaite 2005, Roberts et al. 2011, Näslund et al. 2013, Zhang et al. 2019) and crustaceans (van der Meeren 2001, Carere et al. 2015), but there are indications that effects depend on ontogenetic stage (at least in fish; Rosengren et al. 2017, Zhang et al. 2019). In European lobsters (Homarus gammarus) shelter experience improves the ability to compete for shelters (at least when combined with social rearing), which also translates to higher survival in predator-free mesocosms (Aspaas et al. 2016, Agnalt et al. 2017). Reductions in predation mortality are indicated in laboratory experiments on fish with shelter experience (Kawabata et al. 2011b, but see Crank et al. 2019).

Fish survival (or proxies thereof) have been monitored in nature after release in a few studies, and results have shown that prerelease exposure to shelter-like structures can increase survival, or at least hint at such effects (Kawabata et al. 2011a, D'Anna et al. 2012, Hyvärinen and Rodewald 2013, Roberts et al. 2014, Carrera-García et al. 2017, Mes et al. 2019). However, improved postrelease survival is not detected in all studies, including studies on some species where positive behavioral or cognitive effects have been detected (Brockmark et al. 2007, Fast et al. 2008, Rosengren et al. 2017, Solås et al. 2019). Thus, more studies comparing factors such as species, populations, and types of enrichments used are required for a better picture of what influences the results.

Experience of structural enrichments can also change the microhabitat preference of the reared animals, as seen in cephalopods and fishes (Tatara et al. 2009, Lee et al. 2012, Einfalt et al. 2013, Takahashi and Masuda 2019, but see Berejikian et al. 2000). This may have survival benefits at release into the wild, if the animals quickly seek appropriate environments to reside in instead of lingering in open areas exposed to predators. 
Foraging-related behaviors have been indicated to change in some studies, but results include both positive (Brown et al. 2003a, Beck and Rooker 2008, Rodewald et al. 2011, Ullah et al. 2017, Brignon et al. 2018) and negative effects (Moberg et al. 2011, Rae et al. 2020). Some studies show no detectable differences in foraging between enriched and standard-reared animals (Carrera-García and Rochard 2016, Self et al. 2018, Hatanpää et al. 2020). Differences in results may depend on a variety of factors, like species autecology (comparative studies are unfortunately lacking), which context an animal is tested in (e.g., threatening or benign contexts, warm or cold water, etc.), or which specific behavior is measured (e.g., foraging skill is not necessarily related to foraging efficiency; an individual might be skilled but choose not to forage).

Activity-and exploration-related behaviors have also been shown to either increase (Ullah et al. 2017) or decrease (Moberg et al. 2011, Härkönen et al. 2014, Watz 2019, Watz et al. 2019) in structurally-enriched animals. Again, these differences may depend on context, choice of measurement, or species-specific responses. Relating to measurement choice, Carrera-García and Rochard (2016) showed that European sturgeon (Acipenser sturio) were slower to explore while also having a higher tendency to do so overall. Hence, choosing to measure only one of these behavioral aspects may lead to a different conclusion than measuring both. Variation exists also in change in activity after release into a natural or nature-like environment, even within species. Both Härkönen et al. (2014) and Watz (2019) found that enriched brown trout were less active than standard-reared conspecifics, but while the former study indicated that the activity of the treatment groups quickly converged after release, a difference was maintained in the latter (Watz et al. 2019). Similarly, effects on boldness-like behavioral expression can be either positive (Brignon et al. 2018) or negative (Salvanes and Braithwaite 2005, Lee and Berejikian 2008).

Additional behavioral effects, difficult to group into previous categories, include increased context-dependent shoaling in Atlantic cod (Salvanes et al. 2007), increased social dominance and improved swimming agility in rainbow/steelhead trout (Berejikian et al. 2000, 2001, Tatara et al. 2008, Ahlbeck-Bergendahl et al. 2017), and altered concealment strategies in common cuttlefish (Poirier et al. 2005). Notably, effects seen in laboratory tests are not necessarily translated into increased postrelease performance (e.g., Berejikian et al. 2001, Tatara et al. 2009). Also, some studies have not detected behavioral effects (Riley et al. 2009).

An important aspect of behavior is the variation in expression, both within and among individuals, which has not been discussed in many studies. Effects on behavioral variation (lowered novel prey feeding variance) on the among-individual level has been shown in steelhead trout (Oncorhynchus mykiss; Lee and Berejikian 2008). Such effects, in addition to central-tendency effects, deserve more attention since variance can be biologically significant (Nakagawa et al. 2015).

Another important aspect to consider is the possible interactions with other environmental factors. In Atlantic salmon, enrichment interacts with live-food experience to improve foraging success on novel prey above the levels of either strategy alone (Brown et al 2003a). In the same species, enrichment treatment was found to interact with fish density, affecting both growth and postrelease survival negatively at higher densities (Rosengren et al. 2017). The fact that effects of enrichment vary depending on other environmental factors could potentially explain some of 
the inter-experiment variation in observed results, as different experiments are often run in highly varying experimental settings.

Different types of enrichments could also lead to different effects, and if applied together they could possibly interact to reduce or cancel out effects that would be present if only one type was present. Several studies apply a range of different intank enrichments, current alterations, and life-skills training elements to tanks, in a nonfactorial design (noted specifically in the supplemental data; see Online Supplementary Material). These studies have been included above, under the assumption that the structural enrichment is the main driver of effects. Whether this is true or not, and whether interactive effects exist, can only be found out by applying a factorial (or fractional factorial) design in the experiments (Näslund and Johnsson 2016).

Exposure to Nature-like Social Environments (Density Reduction).Density reduction studies have generally been carried out to lessen stress levels and improve physiological performance in hatchery-reared salmonids. Reduced densities may, for instance, reduce long-term stress, which has potentially negative effects on cognition (Galhardo and Oliveira 2009). In the context of rearing wild-like individuals with appropriate behavioral and cognitive traits, effects are much less explored. However, studies on brown trout indicate that rearing in a reduced, nature-like, density leads to faster prey-location in a maze setup, faster consumption of novel prey, more efficient antipredation behavior, and increased competitive ability (Brockmark and Johnsson 2010, Brockmark et al. 2010). Hence, these studies support the hypothesis that density affects cognitive and behavioral traits in general. One hypothesis is that density reduction makes the social environment more similar to natural conditions, which reduces division of attention and allows for individual decision-making, learning of resource defense, and individual recognition of competitors (Johnsson et al. 2014). A few studies have worked with the hypothesis that high-density environments constitute sensory-deprived environments, as the high number of animals in the tank causes spatial and social homogeneity (Johnsson et al. 2014). Brain development could thereby be expected to suffer, but evidence from brain size measurements in Atlantic salmon does not support this hypothesis, as most brain regions are unaffected, and cerebellum size even increases (Näslund et al. 2017, 2019).

Studies on aggressive salmonid species show that agonistic behavior decreases with increased densities (e.g., Brown et al. 1992). This is a phenomenon widely known among aquaculturists, and high densities are used to avoid aggression in culture. However, while this may improve some aspects of welfare, it may also hinder development of some natural behaviors (which include aggression). Cultured fish from high densities may also develop a suboptimal social behavior after release, such as failed social density-regulation and socially induced dispersal (Jenkins 1971).

Overall, there are several indications that density reduction improves the postrelease survival in salmonids, albeit only to a minor degree in some cases (Fig. 5; Ewing and Ewing 1995). However, the production of animals per unit area will inevitably be lower with reduced rearing density. Hence, without extra space for additional tanks, fewer individuals will be reared for release and the survival must compensate for the lost production. This is rarely the case, but when the ecosystem into which the animals are stocked is sensitive to large numbers of released individuals (e.g., Einum and Fleming 2001), this method could still be potentially suitable. 
The effects of density reduction on behavioral and cognitive traits are clearly underinvestigated and further studies, especially in taxa other than salmonids, are needed.

\section{Discussion and Suggested Future Directions}

While research studies on training procedures or hatchery environment alterations (henceforth "interventions") aimed at improving postrelease performance have shown some interesting and encouraging results, these methods are not as generally successful as earlier review papers predicted a few decades ago (Suboski and Templeton 1989, Brown and Laland 2001). Hence, despite a long history of research in this area, development of appropriate and robust interventions to induce the ecological competence and life-skills needs to be further addressed, following a responsible approach for stocking (Lorenzen et al. 2010). The main take-home messages identified are: (1) results from studies testing similar solutions are often qualitatively variable and therefore seemingly nongeneralizable, (2) systematic studies are required to understand why results differ, including comparative studies involving several different species, and studies including multiple levels of the investigated factors hypothesized to produce more wild-like phenotypes, and (3) more studies on postrelease performance, following the application of promising interventions, are still needed.

Looking at the reviewed studies from a wide taxonomic perspective, there is much information lacking for many species, especially concerning invertebrates and nonsalmonid fish. Even within the relatively well-researched salmonid family many details remain unknown, and the variability in methods applied and resulting effects calls for more systematic approaches in larger-scale experiments, including postrelease trials. Furthermore, more attention to variation among individuals could improve interpretation of the effects of different improvement methods.

With respect to the variability of results, the observed differences across studies could have multiple causes, such as species or life-stage specificity, or just differences in the experimental application of the training protocols (number of trials, time between exposure and test, length of exposure, etc.) or in environmental factors in the rearing units. One life-skills training procedure that deviates from the general variability in results is foraging-training, which more generally leads to rapidly improved foraging abilities. However, the speed at which this occurs suggests that such learning may also be achieved rapidly postrelease and the relatively long time required to starve to death (if released in a good condition) leads to the question of whether this training should be prioritized. The fact that stocked animals (at least fish) often show poor foraging behavior suggests that it is indeed a relevant issue, but more field studies are needed to understand the efficiency of foraging training on postrelease performance in different species. Furthermore, the ability to feed on or recognize natural prey are not the only factors relevant for foraging. Competitive ability and habitat choice in nature will also likely play significant parts in foraging success. Density reduction experiments are relatively stable in the direction of effects on postrelease performance (although magnitude of effects differ substantially), but it is also generally recognized that reduction requires substantially more space to compensate for lower production per area of hatchery space. Furthermore, salmonid fish are virtually the only taxa that have been tested (Fig. 5) and only a few 
A
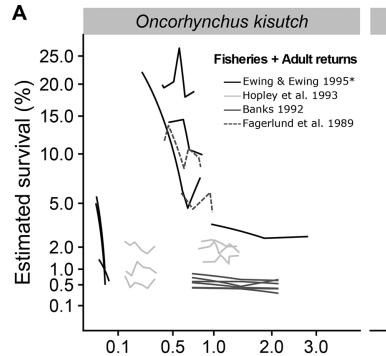

Oncorhynchus tshawytscha

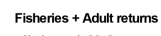

- Clarke et al. 2013

Banks \& LaMotte 2002
-Banks 1994 Marnes et al. 2013
--Fagerlund ethet al. 1987
- 1989
…-...-. Dentortun 1988
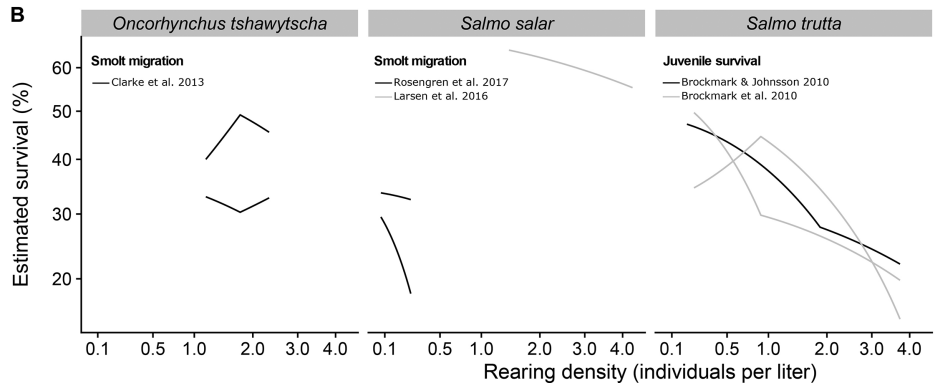

Figure 5. Visual overview of estimated mean survivability of hatchery reared salmonids in the wild, depending on rearing density (measured as individuals per liter) from empirical studies. (A) Survivability based on adult returns to the natal river and/or fisheries data. (B) Survivability based on juvenile survival in streams or successful downstream smolt migration. Data from different studies may not be directly comparable due to different rearing conditions and estimation methods; comparable data are connected with lines. Note that axes are square-root transformed, explaining the curved lines between point estimates. * Data from empirical studies reported in Ewing and Ewing 1995. Raw data used to construct the figure are deposited in the figshare repository (see Online Supplementary Material).

studies have investigated the actual behavioral effects of this rearing modification (e.g., Brockmark and Johnsson 2010, Brockmark et al. 2010).

Concerning postrelease performance studies, these constitute a category of studies that are surprisingly rare, given the fact that the ultimate aim of the research is to improve postrelease performance. Admittedly, postrelease studies are often difficult and expensive, but they are also necessary to confirm inductions based on laboratory results. Even if promising results are found in the laboratory, the effects may differ in more complex natural environments. Many training procedures and altered rearing environments are associated with increased production costs, and positive postrelease effects should preferably be ascertained before suggesting implementation of a new rearing strategy.

Overall, with the present state of knowledge, it is difficult to present a good assessment of how far we can come in improving postrelease performance of stocked aquatic animals. In many cases, we are still at the stage of testing different strategies in species-specific case studies, rather than refining or generalizing the methodology. If one also assumes a publication bias towards positive (or at least statistically "significant") findings, then the progress may even be less than perceivable from the literature. Furthermore, one piece of information that is missing in the current scientific literature is an evaluation of how widely used life-skills training, enrichment, and density reduction schemes are in aquaculture producing animals for stocking. A systematic global survey could improve this picture. 
A number of seemingly relevant questions for future research (representing gaps in knowledge) arose from the present review. Many of these are general for all kinds of interventions. While some are difficult to address, others should be quite easy to implement in future or even ongoing research projects.

- How do different species and populations react to intervention? Are some species or populations more or less influenced than others? Comparative studies are largely missing, particularly at the species level, but could help in building knowledge about how ecological traits are important for performance under different culture conditions.

- How do different ontogenetic stages of a species respond to interventions? Does it matter at which life-stage an intervention is introduced? Existing studies suggest there are potentially important effects that need further exploration in more species and in postrelease studies.

- What is the effect of genetic diversity in the reared animals on different intervention outcomes? For example, is there a genetic component affecting the responsiveness to interventions? If so, broodstock variation would be a very important factor to consider, in addition to preparing the animals for a life in nature.

- How are different phenotypes [relating to behavior ("personality"), morphology, coloration, stress responsiveness, etc.] affected by interventions? Are specific phenotypes promoted over others when an intervention is applied and, if so, how does the surviving part of the stocked population compare with the phenotype distribution of natural populations and standard-reared groups? Do different phenotypes require different amounts of training (e.g., different numbers of live-food exposures, depending on level of neophobia)?

- Which behavioral and cognitive traits are critical for postrelease performance, and which are not? How much do cultured animals differ from wild ones in those traits? That is, what are the specific goals when aiming for culturing a wild-like phenotype? Few studies specify end goals for their interventions, apart from a vague aim of improved performance.

- How can successful experimental results be applied in large-scale production? More large-scale studies following up on results from small laboratory experiments are needed; several studies suggest that scale matters.

- What is the timespan of intervention effects? How long is the memory window of the learned skills, and how much does it vary among individuals? For how long postrelease do cultured animals from an altered environment differ compared to standard-reared and wild individuals?

- How does retention of effects depend on the level of exposure (e.g., number of learning trials, length of training trials, or length of exposure to an altered environment)? Information on this makes it possible to distinguish whether animals are reinforced or habituated during repeated or prolonged interventions and makes optimization of interventions in relation to stocking date possible. It is important to note that memory retention is not general for all types 
of stimuli (see example Kaneko et al. 2019), so each training program needs to assess this separately.

- Can the cultured animals generalize learned responses to situations similar, but not identical, to the training situation? Responses to different types of food or predators after conditioning training need to be measured to understand how generalized the trained responses are.

- How do different varieties of the same type of factor (e.g., different prey species, predator cues, enrichment structures, etc.) affect performance? This information is required to get a picture of the generality of responses to a specific intervention, and to optimize the intervention.

- How do different levels of the same factor, along continuous scales (e.g., different length of exposure, amounts of enrichment structures, or densities) affect performance? This is important to detect nonlinear patterns and to optimize interventions.

- How do different types of interventions interact? This is important to find out whether we get additive or non-additive (either more or less than additive) effects of applying several types of interventions.

As a final note for future studies, it is again important to stress the current variation in results related to a certain type of intervention. To gain a more complete picture of what the effects are for each relevant species, and identify key factors causing variation in results, it is important to conduct more studies, not least different types of intra- and interspecific replication studies (see Kelly 2006), and to report the results in publications in a balanced and clear way, even if results are negative or inconclusive (Daly et al. 2020). Reporting of replication studies and negative or inconclusive results relies on the scientific journals (especially fisheries and aquaculture journals) taking responsibility to publish these results. In addition, it is advisable for researchers writing up their work to (1) be very clear about all methodology involved in the experiment (time courses, dates, environmental factors, disturbances, test conditions, tank size, etc.), and (2) be explicit about whether assumptions and comparisons are made with reference to previous results from the same study species or not, since information from other species than the studied species may not be very relevant.

\section{ACKNOWLEDGMENTS}

I thank the two anonymous reviewers and the section editor for excellent suggestions and advice for improving earlier versions of the manuscript. The paper is dedicated to the memory of Jörgen Johnsson, who passed away way too early. Large parts of the content are influenced by his thoughts and ideas. 


\section{Literature Cited}

Abramson CI, Feinman RD. 1990. Operant conditioning in the crab. In: Wiese K, Krenz W-D, Tautz J, Reichert H, Mulloney B, editors. Frontiers in crustacean neurobiology. Basel: Birkhäuser. p. 207-214.

Adriaenssens B, Johnsson JI. 2011. Learning and context-specific exploration behaviour in hatchery and wild brown trout. Appl Anim Behav Sci. 132(1-2):90-99. https://doi. org/10.1016/j.applanim.2011.03.005

Agnalt AL, Grefsrud ES, Farestveit E, Jørstad KE. 2017. Training camp-a way to improve survival in European lobster juveniles? Fish Res. 186(2):531-537. https://doi.org/10.1016/j. fishres.2016.09.021

Ahlbeck Bergendahl I, Miller S, Depasquale C, Giralico L, Braithwaite VA. 2017. Becoming a better swimmer: structural complexity enhances agility in a captive-reared fish. J Fish Biol. 90(3):1112-1117. https://doi.org/10.1111/jfb.13232

Ahlbeck Bergendahl I, Salvanes AGV, Braithwaite VA. 2016. Determining the effects of duration and recency of exposure to environmental enrichment. Appl Anim Behav Sci. 176:163-169. https://doi.org/10.1016/j.applanim.2015.11.002

Álvarez D, Nicieza AG. 2003. Predator avoidance behaviour in wild and hatchery-reared brown trout: the role of experience and domestication. J Fish Biol. 63(6):1565-1577. https://doi. org/10.1111/j.1095-8649.2003.00267.x

Arai T, Tominaga O, Seikai T, Masuda R. 2007. Observational learning improves predator avoidance in hatchery-reared Japanese flounder Paralichthys olivaceus juveniles. J Sea Res. 58(1):59-64. https://doi.org/10.1016/j.seares.2007.01.004

Araki H, Berejikian BA, Ford MJ, Blouin MS. 2008. Fitness of hatchery-reared salmonids in the wild. Evol Appl. 1(2):342-355. https://doi.org/10.1111/j.1752-4571.2008.00026.x

Archer SK, Crowl TA. 2014. Retention of learned predator recognition in an endangered sucker Chasmistes liorus liorus. Aquat Biol. 20(3):195-202. https://doi.org/10.3354/ab00558

Aspaas S, Grefsrud ES, Fernö A, Jensen KH, Trengereid H, Agnalt A-L. 2016. An enriched environment promotes shelter-seeking behaviour and survival of hatchery-produced juvenile European lobster (Homarus gammarus). PLOS ONE. 11(8):e0159807. https://doi. org/10.1371/journal.pone.0159807

Aspillaga E, Arlinghaus R, Martorell-Barceló M, Follana-Berná G, Lana A, Campos-Candela A, Alós J. 2021. Performance of a novel system for high-resolution tracking of marine fish societies. Anim Biotelem. 9:1. https://doi.org/10.1186/s40317-020-00224-w

Ayub N, Benton JL, Zhang Y, Beltz BS. 2011. Environmental enrichment influences neuronal stem cells in the adult crayfish brain. Dev Neurobiol. 71(5):351-361. https://doi. org/10.1002/dneu.20864

Banks JL. 1992. Effects of density and loading on coho salmon during hatchery rearing and after release. Progr Fish-Cult. 54(3):137-147. https://doi.org/10.1577/1548-8640(1992)054<0137

Banks JL. 1994. Raceway density and water flow as factors affecting spring chinook salmon (Oncorhynchus tshawytscha) during rearing and after release. Aquaculture. 119(2-3):201217. https://doi.org/10.1016/0044-8486(94)90176-7

Banks JL, LaMotte EM. 2002. Effects of four density levels on Tule fall chinook salmon during hatchery rearing and after release. N Am J Aquacult. 64(1):24-33. https://doi. org/10.1577/1548-8454(2002)064<0024:EOFDLO>2.0.CO;2

Barnes ME, Wipf MM, Domenici NR, Kummer WM, Hanten RP. 2013. Decreased hatchery rearing density improves poststocking harvest and return to spawning of landlocked fall chinook salmon. N Am J Aquacult. 75(2):244-250. https://doi.org/10.1080/15222055.201 3.768573

Beck JL, Rooker JR. 2008. The effect of habitat exposure and ontogeny on the survival skills of hatchery red drum. N Am J Aquacult. 70(4):399-409. https://doi.org/10.1577/A07-087.1

Beck JL, Rooker JR. 2012. Effect of predator exposure on the performance and survival of red drum (Sciaenops ocellatus). Environ Biol Fish. 93:267-276. https://doi.org/10.1007/ s10641-011-9912-1 
Bell JD, Rothlisberg PC, Munro JL, Loneragan NR, Nash WJ, Ward RD, Andrew NL. 2005. Restocking and stock enhancement of marine invertebrate fisheries. Adv Mar Biol. 49:1-7. https://doi.org/10.1016/S0065-2881(05)49001-X

Benhaïm D, Bégout ML, Lucas G, Chatain B. 2013. First insight into exploration and cognition in wild caught and domesticated sea bass (Dicentrarchus labrax) in a maze. PLOS ONE. 8(6):e65872. https://doi.org/10.1371/journal.pone.0065872

Berejikian BA. 1995. The effects of hatchery and wild ancestry and experience on the relative ability of steelhead trout fry (Oncorhynchus mykiss) to avoid a benthic predator. Can J Fish Aquat Sci. 52(11):2476-2482. https://doi.org/10.1139/f95-838

Berejikian BA, Smith RJF, Tezak EP, Schroder SL, Knudsen CM. 1999. Chemical alarm signals and complex hatchery rearing habitats affect antipredator behavior and survival of chinook salmon (Oncorhynchus tshawytscha) juveniles. Can J Fish Aquat Sci. 56(5):830-838. https://doi.org/10.1139/f99-010

Berejikian BA, Tezak EP, Flagg TA, LaRae AL, Kummerow E, Mahnken CVW. 2000. Social dominance, growth, and habitat use of age-0 steelhead (Oncorhynchus mykiss) grown in enriched and conventional hatchery rearing environments. Can J Fish Aquat Sci. 57(3):628636. https://doi.org/10.1139/f99-288

Berejikian BA, Tezak EP, LaRae AL. 2003. Innate and enhanced predator recognition in hatchery-reared chinook salmon. Environ Biol Fish. 67(3):241-251. https://doi. org/10.1023/A:1025887015436

Berejikian BA, Tezak EP, Riley SC, LaRae AL. 2001. Competitive ability and social behaviour of juvenile steelhead reared in enriched and conventional hatchery tanks and a stream environment. J Fish Biol. 59(6):1600-1613. https://doi.org/10.1111/j.1095-8649.2001.tb00224.x

Bertapelle C, Polese G, Di Cosmo A. 2017. Enriched environment increases PCNA and PARP1 levels in Octopus vulgaris central nervous system: first evidence of adult neurogenesis in Lophotrochozoa. J Exp Zool Part B. 328(4):347-359. https://doi.org/10.1002/jez.b.22735

Bettinger JM, Bettoli PW. 2002. Fate, dispersal, and persistence of recently stocked and resident rainbow trout in a Tennessee tailwater. N Am J Fish Manag. 22(2):425-432. https://doi. org/10.1577/1548-8675(2002)022<0425:FDAPOR >2.0.CO;2

Blaxter JHS. 1970. Sensory deprivation and sensory input in rearing experiments. Helgol Wiss Meeresunters. 20(1-4):642-654. https://doi.org/10.1007/BF01609937

Blaxter JHS. 2000. The enhancement of marine fish stocks. Adv Mar Biol. 38:1-54. https://doi. org/10.1016/S0065-2881(00)38002-6

Bolland JD, Cowx IG, Lucas MC. 2008. Movements and habitat use of wild and stocked juvenile chub, Leuciscus cephalus (L.), in a small lowland river. Fish Manag Ecol. 15(5-6):401-407. https://doi.org/10.1111/j.1365-2400.2008.00631.x

Braithwaite VA, Salvanes AGV. 2005. Environmental variability in the early rearing environment generates behaviourally flexible cod: implications for rehabilitating wild populations. Proc R Soc B. 272(1568):1107-1113. https://doi.org/10.1098/rspb.2005.3062

Brännäs E, Johnsson JI. 2008. Behaviour and welfare in farmed fish. In: Magnhagen C, Braithwaite VA, Forsgren E, Kapoor BG, editors. Fish behaviour. Boca Raton: CRC Press. p. 607-642.

Brennan NP, Darcy MC, Leber KM. 2006. Predator-free enclosures improve postrelease survival of stocked common snook. J Exp Mar Biol Ecol. 335(2):302-311. https://doi.org/10.1016/j. jembe.2006.04.001

Briffa M, Weiss A. 2010. Animal personality. Trends Ecol Evol. 20:R912-R914.

Brignon WR, Pike MM, Peterson JT, Schreck CB. 2018. Rearing environment influences boldness and prey acquisition behavior, and brain and lens development of bull trout. Environ Biol Fish. 101(3):383-401. https://doi.org/10.1007/s10641-017-0705-z

Brockmark S, Adriaenssens B, Johnsson JI. 2010. Less is more: density influences the development of behavioural life skills in trout. Proc R Soc B. 277:3035-3043. https://doi. org/10.1098/rspb.2010.0561 
Brockmark S, Johnsson JI. 2010. Reduced hatchery rearing density increases social dominance, postrelease growth, and survival in brown trout (Salmo trutta). Can J Fish Aquat Sci. 67(2):288-295. https://doi.org/10.1139/F09-185

Brockmark S, Neregård L, Bohlin T, Björnsson BT, Johnsson JI. 2007. Effects of rearing density and structural complexity on the pre- and postrelease performance of Atlantic salmon. Trans Am Fish Soc. 136(5):1453-1462. https://doi.org/10.1577/T06-245.1

Broglio C, Gómez A, Durán E, Salas C, Rodríguez F. 2011. Brain and cognition in teleost fish. In: Brown C, Laland K, Krause J, editors. Fish cognition and behavior. 2nd ed. London: Wiley-Blackwell. p. 325-358.

Brokordt KB, Fernández M, Gaymer CF. 2006. Domestication reduces the capacity to escape from predators. J Exp Mar Biol Ecol. 329(1):11-19. https://doi.org/10.1016/j. jembe.2005.08.007

Brokordt KB, Núñez GA, Gaymer CF. 2011. Improving escape responses of hatchery-reared scallops Argopecten purpuratus. Mar Biol. 158(6):1311-1318. https://doi.org/10.1007/ s00227-011-1650-6

Browman HI. 1989. Embryology, ethology and ecology of ontogenetic critical periods in fish. Brain Behav Evol. 34(1):5-12. https://doi.org/10.1159/000116486

Brown AD, Sisneros JA, Jurasin T, Ngyen C, Coffin AB. 2013b. Differences in lateral line morphology between hatchery- and wild-origin steelhead. PLOS ONE. 8(3):e59162. https://doi. org/10.1371/journal.pone.0059162

Brown C. 2015. Fish intelligence, sentience and ethics. Anim Cogn. 18(1):1-17. https://doi. org/10.1007/s10071-014-0761-0

Brown C, Davidson T, Laland K. 2003a. Environmental enrichment and prior experience of live prey improve foraging behaviour in hatchery-reared Atlantic salmon. J Fish Biol. 63:187196. https://doi.org/10.1111/j.1095-8649.2003.00208.x

Brown C, Laland KN. 2001. Social learning and life skills training for hatchery reared fish. J Fish Biol. 59(3):471-493. https://doi.org/10.1111/j.1095-8649.2001.tb02354.x

Brown C, Laland K. 2002. Social enhancement and social inhibition of foraging behaviour in hatchery-reared Atlantic salmon. J Fish Biol. 61:987-998. https://doi. org/10.1111/j.1095-8649.2002.tb01857.x

Brown C, Markula A, Laland K. 2003b. Social learning of prey location in hatchery-reared Atlantic salmon. J Fish Biol. 63:738-745. https://doi.org/10.1046/j.1095-8649.2003.00186.x

Brown GE. 2003. Learning about danger: chemical alarm cues and risk assessment in prey fishes. Fish Fish. 4(3):227-234. https://doi.org/10.1046/j.1467-2979.2003.00132.x

Brown GE, Brown JA, Srivastava RK. 1992. The effect of stocking density on the behaviour of Arctic charr (Salvelinus alpinus L.). J Fish Biol. 41(6):955-963. https://doi. org/10.1111/j.1095-8649.1992.tb02722.x

Brown GE, Ferrari MCO, Chivers DP. 2013a. Adaptive forgetting: why predator recognition training might not enhance poststocking survival. Fisheries. 38(1):16-25. https://doi.org/1 $0.1080 / 03632415.2013 .750133$

Brown GE, LeBlanc VJ, Hunter LE. 2001. Ontogenetic changes in the response of largemouth bass (Micropterus salmoides, Centrarchidae, Perciformes) to heterospecific alarm pheromones. Ethology. 107(5):401-414. https://doi.org/10.1046/j.1439-0310.2001.00671.x

Brown GE, Smith RJF. 1998. Acquired predator recognition in juvenile rainbow trout (Oncorhynchus mykiss): conditioning hatchery-reared fish to recognize chemical cues of a predator. Can J Fish Aquat Sci. 55:611-617. https://doi.org/10.1139/f97-261

Burns JG, Rodd FH. 2008. Hastiness, brain size and predation regime affect the performance of wild guppies in a spatial memory task. Anim Behav. 76(3):911-922. https://doi. org/10.1016/j.anbehav.2008.02.017

Burns JG, Saravanan A, Rodd FH. 2009. Rearing environment affects the brain size of guppies: lab-reared guppies have smaller brains than wild-caught guppies. Ethology. 115(2):122133. https://doi.org/10.1111/j.1439-0310.2008.01585.x 
Caldentey P, Brennan NP, Heimann T, Gardiner JM. 2021. Prey capture kinematics of wild and hatchery juvenile common snook Centropomus undecimalis. Bull Mar Sci. 97(4):539-558. https://do1.org/10.5343/bms.2020.0023

Cámara-Ruiz M, Santo CE, Gessner J, Wuertz S. 2019b. How to improve foraging efficiency for restocking measures of juvenile Baltic sturgeon (Acipenser oxyrinchus). Aquacult. 502:1217. https://doi.org/10.1016/j.aquaculture.2018.12.021

Cámara Ruiz M, Santo CE, Mai A, Gessner J, Wuertz S. 2019a. Can juvenile Baltic sturgeon (Acipenser oxyrinchus) smell the enemy? J Appl Ichthyol. 35(4):835-842. https://doi. org/10.1111/jai.13934

Carere C, Nascetti G, Carlini A, Santucci D, Alleva E. 2015. Actions for restocking of the European lobster (Homarus gammarus): a case study on the relevance of behaviour and welfare assessment of cultured juveniles. Rend Fis Acc Lincei. 26(1):59-64. https://doi. org/10.1007/s12210-014-0361-6

Carrera-García E, Rochard E. 2016. European sturgeon (Acipenser sturio L.) young of the year performance in different rearing environments - study within a stocking program. Environ Biol Fish. 99(11):887-901. https://doi.org/10.1007/s10641-016-0531-8

Carrera-García E, Rochard E, Acolas M. 2017. Effects of rearing practice on postrelease youngof-the-year behavior: Acipenser sturio early life in freshwater. Endang Species Res. 34:269281. https://doi.org/10.3354/esr00854

Cauchoix M, Chaine AS, Barragan-Jason G. 2020. Cognition in context: plasticity in cognitive performance in response to ongoing environmental variables. Front Ecol Evol. 8:106. https://doi.org/10.3389/fevo.2020.00106

Chapple DG, Simmonds SM, Wong BBM. 2012. Can behavioral and personality traits influence the success of unintentional species introductions? Trends Ecol Evol. 27(1):57-64. https:// doi.org/10.1016/j.tree.2011.09.010

Chittenden CM, Biagi CA, Davidsen JG, Davidsen AG, Kondo H, McKnight A, Pedersen O-P, Raven PA, Rikardsen AH, Shrimpton JM, et al. 2010. Genetic versus rearing-environment effects on phenotype: hatchery and natural rearing effects on hatchery- and wild-born coho salmon. PLOS ONE. 5(8):e12261. https://doi.org/10.1371/journal.pone.0012261

Christie MR, Marine ML, Fox SE, French RA, Blouin MS. 2016. A single generation of domestication heritably alters the expression of hundreds of genes. Nat Commun. 7:10676. https:// doi.org/10.1038/ncomms10676

Ciszewski K, Czerniejewski P, Wawrzyniak W, Surma O. 2020. Predatory reactions of juvenile stages of sea trout Salmo trutta trutta (L., 1758) fed with three feeding regimens. Iran J Fish Sci. 19(1):182-194. https://doi.org/10.22092/ijfs.2019.118392

Clarke LR, Cameron WA, Carmichael RW. 2013. Density effects on subyearling fall chinook salmon during hatchery rearing in raceways with oxygen supplementation and after release. N Am J Aquacult. 75(1):18-24. https://doi.org/10.1080/15222055.2012.711276

Coble DW, Farabee GB, Anderson RO. 1985. Comparative learning ability of selected fishes. Can J Fish Aquat Sci. 42(4):791-796. https://doi.org/10.1139/f85-101

Cogliati KM, Unrein JR, Schreck CB, Noakes DL. 2019. Rearing environment affects spatial learning in juvenile chinook salmon Oncorhynchus tshawytscha. J. Fish Biol. 95(3):870-880. https://do1.org/10.1111/ftb.14083

Colgan PW, Brown JA, Orsatti SD. 1986. Role of diet and experience in the development of feeding behavior in largemouth bass, Micropterus salmoides. J Fish Biol. 28(2):161-170. https://doi.org/10.1111/j.1095-8649.1986.tb05154.x

Cordero-Rivera A. 2017. Behavioral diversity (ethodiversity): a neglected level in the study of biodiversity. Front Ecol Evol. 5:7. https://doi.org/10.3389/fevo.2017.00007

Costas N, Álvarez M, Pardo I. 2013. Stocking efficiency and the effects of diet preconditioning on the postrelease adaptation of hatchery-reared juveniles of Atlantic salmon (Salmo salar L.) in an Atlantic temperate stream. Environ Biol Fish. 96(1):33-44. https://doi. org/10.1007/s10641-012-0020-7 
Cowx IG. 1994. Stocking strategies. Fish Manag Ecol. 1(1):15-30. https://doi. org/10.1111/j.1365-2400.1970.tb00003.x

Crane AL, Lampe MJ, Mathis A. 2015. Maladaptive behavioural phenotypes in captive reared darters (Etheostoma caeruleum, Storer 1845). J Appl Ichthyol. 31(4):787-792. https://doi. org/10.1111/jai.12769

Crane AL, Mathis A. 2011. A conservation strategy to increase postrelease survival of hellbenders in head-starting programs. Zoo Biol. 30(6):611-622. https://doi.org/10.1002/zoo.20358

Crank KM, Voorhees JM, Barnes ME. 2019. Predator avoidance of rainbow trout reared with environmental enrichment. J Fish Aquacult Dev. 3(1):1047. https://doi. org/10.29011/2577-1493.101047

Crossman JA, Forsythe PS, Scribner KT, Baker EA. 2011. Hatchery rearing environment and age affect survival and movements of stocked juvenile lake sturgeon. Fish Managem Ecol. 18(2):132-144. https://doi.org/10.1111/j.1365-2400.2010.00762.x

Cucherousset J, Olden JD. 2020. Are domesticated freshwater fish an underappreciated culprit of ecosystem change? Fish Fish. 21(6):1253-1258. https://doi.org/10.1111/faf.12499

Czerniawski R, Domagała J, Krepski T, Pilecka-Rapacz M. 2015. The effect of the live diet given to hatchery-reared fry of the European grayling (Thymallus thymallus) on their survival and growth in the wild. Turk J Fish Aquat Sci. 15(3):633-638. https://doi. org/10.4194/1303-2712-v15_3_07

Czerniawski R, Pilecka-Rapacz M, Domagała J. 2010. Growth and survival of brown trout fry (Salmo trutta m. fario) in the wild, reared in the hatchery on different feed. Electr J Pol Agricult Uni. 13(2):art04. Available from: http://www.ejpau.media.pl/volume13/issue2/art04.html

Czerniawski R, Pilecka-Rapacz M, Domagała J. 2011. Stocking experiment with Atlantic salmon and sea trout parr reared on either live prey or a pelleted diet. J Appl Ichthyol. 27(4):984-989. https://doi.org/10.1111/j.1439-0426.2011.01761.x

D’Anna G, Giacalone VM, Fernández TV, Vaccaro AM, Pipitone C, Mirto S, Mazzola S, Badalamenti F. 2012. Effects of predator and shelter conditioning on hatchery-reared white seabream Diplodus sargus (L., 1758) released at sea. Aquaculture. 356-357:91-97. https:// doi.org/10.1016/j.aquaculture.2012.05.032

Dalesman S, Lukowiak K. 2011. Social snails: the effect of social isolation on cognition is dependent on environmental context. J Exp Biol. 214:4179-4185. https://doi.org/10.1242/ jeb.064857

Dall SRX, Giraldeau L-A, Olsson O, McNamara JM, Stephens DW. 2005. Information and its use by animals in evolutionary ecology. Trends Ecol Evol. 20(4):187-193. https://doi. org/10.1016/j.tree.2005.01.010

Daly BJ, Eckert GL, Long WC. 2020. Moulding the ideal crab: implications of phenotypic plasticity for crustacean stock enhancement. ICES J Mar Sci. 78(1):421-434. https://doi. org/10.1093/icesjms/fsaa043

Daly BJ, Stoner AW, Eckert GL. 2012. Predator-induced behavioral plasticity of juvenile red king crabs (Paralithodes camtschaticus). J Exp Mar Biol Ecol. 429:47-54. https://doi. org/10.1016/j.jembe.2012.06.010

Darmaillacq A-S, Lesimple C, Dickel L. 2008. Embryonic visual learning in the cuttlefish, Sepia officinalis. Anim Behav. 76(1):131-134. https://doi.org/10.1016/j.anbehav.2008.02.006

Davison W. 1997. The effects of exercise training on teleost fish, a review of recent literature. Comp Biochem Physiol Part A Physiol. 117(1):67-75. https://doi.org/10.1016/ S0300-9629(96)00284-8

Davis JLD, Eckert-Mills MG, Young-Williams AC, Hines AH, Zohar Y. 2005. Morphological conditioning of a hatchery-raised invertebrate, Callinectes sapidus, to improve field survivorship after release. Aquaculture. 243:147-158. https://doi.org/10.1016/j. aquaculture.2004.09.027

Delgado GA, Glazer RA, Stewart NJ. 2002. Predator-induced behavioral and morphological plasticity in the tropical marine gastropod Strombus gigas. Biol Bull. 203(1):112-120. https://doi.org/10.2307/1543463 
Denton C. 1988. Marine survival of chinook salmon, Oncorhynchus tshawytscha, reared at three densities. FRED Reports 88. Juneau: Alaska Department of Fish and Game.

Deverill JI, Adams CE, Bean CW. 1999. Prior residence, aggression and territory acquisition in hatchery-reared and wild brown trout. J Fish Biol. 55(4):868-875. https://doi. org/10.1111/j.1095-8649.1999.tb00723.x

Diana MJ, Diffin BJ, Einfalt LM, Wahl DH. 2018. Effect of rearing experience on the survival, growth, and behavior of hatchery-reared largemouth bass. N Am J Fish Manag. 38(4):794802. https://doi.org/10.1002/nafm.10175

Dickel L, Boal JG, Budelmann BU. 2000. The effect of early experience on learning and memory in cuttlefish. Dev Psychobiol. 36(2):101-110. https://doi.org/10.1002/ (SICI)1098-2302(200003)36:2<101::AID-DEV2>3.0.CO;2-L

Donadelli V, Longobardi A, Finoia MG, Marino G. 2015. Feeding hatchery-reared dusky grouper Epinephelus marginatus juveniles on live prey: implications for restocking. Environ Biol Fish. 98(7):1757-1766. https://doi.org/10.1007/s10641-015-0395-3

Ebbesson LOE, Braithwaite VA. 2012. Environmental effects on fish neural plasticity and cognition. J Fish Biol. 81(7):2151-2174. https://doi.org/10.1111/j.1095-8649.2012.03486.x

Ebner BC, Thiem JD. 2009. Monitoring by telemetry reveals differences in movement and survival following hatchery or wild rearing of an endangered fish. Mar Freshw Res. 60(1):4557. https://doi.org/10.1071/MF08027

Ebner BC, Thiem JD, Lintermans M. 2007. Fate of 2 year-old, hatchery-reared trout cod Maccullochella macquariensis (Percichthyidae) stocked into two upland rivers. J Fish Biol. 71(1):182-199. https://doi.org/10.1111/j.1095-8649.2007.01481.x

Einfalt LM, Wojcieszak DB, Wahl DH. 2013. Behavior, growth and habitat selection of hatchery esocids reared with artificial vegetation. Trans Am Fish Soc. 142(2):345-352. https://doi.or g/10.1080/00028487.2012.741552

Einum S, Fleming IA. 2001. Implications of stocking: ecological interactions between wild and released fish. Nord J Freshw Res. 75:56-70.

Ellis T, Howell BR, Hughes RN. 1997. The cryptic responses of hatchery-reared sole to a natural sand substratum. J Fish Biol. 51(2):389-401. https://doi.org/10.1111/j.1095-8649.1997. tb01674.x

Ellis T, Hughes RN, Howell BR. 2002. Artificial dietary regime may impair subsequent foraging behaviour of hatchery-reared turbot released into the natural environment. J Fish Biol. 61(1):252-264. https://doi.org/10.1111/j.1095-8649.2002.tb01750.x

Elrod JH, Ostergaard DE, Schneider CP. 1989. Effect of rearing density on poststocking survival of lake trout in Lake Ontario. Prog Fish-Cult. 51(4):189-193. https://doi. org/10.1577/1548-8640(1989)051<0189:EORDOP>2.3.CO;2

Ewing RD, Ewing SK. 1995. Review of the effects of rearing density on survival to adulthood for Pacific salmon. Prog Fish-Cult. 57(1):1-25. https://doi. org/10.1577/1548-8640(1995)057<0001:ROTEOR>2.3.CO;2

Fagerlund UHM, McBride JR, Dosanjh BS, Stone ET. 1987. Culture density and size effects on performance to release of juvenile chinook salmon and subsequent ocean survival. Smolt releases from Capilano Hatchery in 1980 and 1981. Can Tech Rep Fish Aquat Sci. No. 1572.

Fagerlund UH, McBride MJR, Dosanjh BS, Van Tine J, Greig M. 1989. Effects of culture density and size of juveniles on growth and survival of pond-reared coho salmon released from Quinsam Hatchery in 1983 and 1984. Can Tech Rep Fish Aquat Sci. No. 1689.

Fairchild EA, Howell WH. 2004. Factors affecting the postrelease survival of cultured juvenile Pseudopleuronectes americanus. J Fish Biol. 65 s1:69-87. https://doi. org/10.1111/j.0022-1112.2004.00529.x

Fast DE, Neeley D, Lind DT, Johnston MV, Strom CR, Bosch WJ, Knudsen CM, Schoder SL, Watson BD. 2008. Survival comparison of spring chinook salmon reared in a production hatchery under optimum conventional and seminatural conditions. Trans Am Fish Soc. 137(5):1507-1518. https://doi.org/10.1577/T07-143.1 
Fernö A, Huse G, Jakobsen PJ, Kristiansen TS, Nilsson J. 2011. Fish behaviour, learning, aquaculture and fisheries. In: Brown C, Laland K, Krause J, editors. Fish cognition and behavior. 2nd ed. London: Wiley-Blackwell. p. 359-404.

Fitzwater ME, Reisman MN. 1952. Comparisons of forward, simultaneous, backward, and pseudo-conditioning. J Exp Psychol. 44(3):211-214. https://doi.org/10.1037/h0060495

Fjellheim A, Raddum GG, Barlaup BT. 1995. Dispersal, growth and mortality of brown trout (Salmo trutta L.) stocked in a regulated West Norwegian river. Regul Rivers Res Manag. 10(2-4):137-145. https://doi.org/10.1002/rrr.3450100209

Fortney R. 1939. Naturalistic raceways. Prog Fish-Cult. 6(47):53-54. https://doi. org/10.1577/1548-8640(1939)6[53:NR]2.0.CO;2

Franssen NR, Durst SL, Gilbert EI, Knight WK, Ulibarri M. 2021. Flow conditioning of hatchery-reared razorback sucker increases apparent survival in the wild. N Am J Fish Managem. https://doi.org/10.1002/nafm.10564

Fraser DJ, Walker L, Yates MC, Marin K, Wood JLA, Bernos TA, Zastavniouk C. 2019. Population correlates of rapid captive-induced maladaptation in a wild fish. Evol Appl. 12:1305-1317. https://doi.org/10.1111/eva.12649

Fraser JM. 1974. An attempt to train hatchery-reared brook trout to avoid predation by the common loon. Trans Am Fish Soc. 103(4):815-818. https://doi. org/10.1577/1548-8659(1974)103<815:AATTHB >2.0.CO;2

Fujii T, Noguchi M. 1993. Interactions between released and wild Japanese flounder (Paralichthys olivaceus) on a nursery ground. Proc U S Jpn Aquacult Panel Symp. 22:57-65.

Fujikawa Y, Sasaki T. 2001. Learning effect on predator avoidance in hatchery-reared juveniles of the red sea bream, Pagrus major. Suisan Zoshoku. 49:151-156. https://doi.org/10.11233/ aquaculturesci1953.49.151

Furuta S, Watanabe T, Yamada H. 1998. Predation by fishes on hatchery reared Japanese flounder Paralichthys olivaceus juveniles released in the coastal area of Tottori Prefecture. Nippon Suisan Gakkaishi. 64(1):1-7. https://doi.org/10.2331/suisan.64.1

Galhardo L, Oliveira RF. 2009. Psychological stress and welfare in fish. Ann Rev Biomed Sci. 11:120. http://arbs.biblioteca.unesp.br/index.php/arbs/article/view/1806-8774.2009v11p1/113

Gall BG, Mathis A. 2010. Innate preator recognition and the problem of introduced trout. Ethology. 116(1):47-58. https://doi.org/10.1111/j.1439-0310.2009.01718.x

Garock TM, Monk CT, Lorenzen K, Matthews MD, St Mary CM. 2014. Effects of hatchery rearing on Florida largemouth bass Micropterus floridanus resource allocation and performance under semi-natural conditions. J Fish Biol. 85(6):1830-1842. https://doi. org/10.1111/jfb.12514

Gering E, Incorvaia D, Henriksen R, Wright D, Getty T. 2019. Maladaptation in feral and domesticated animals. Evol Appl. 12:1274-1286. https://doi.org/10.1111/eva.12784

Gomez-Pinilla F, Hillman C. 2013. The influence of exercise on cognitive abilities. Compr Physiol. 3(1):403-428. https://doi.org/10.1002/cphy.c110063

Ginetz RM, Larkin PA. 1976. Factors affecting rainbow trout (Salmo gairdneri) predation on migrant fry of sockeye salmon (Oncorhynchus nerka). J Fish Res Board Can. 33(1):19-24. https://doi.org/10.1139/f76-003

Greggor AL, Clayton NS, Phalan B, Thornton A. 2014. Comparative cognition for conservationists. Trends Ecol Evol. 29(9):489-495. https://doi.org/10.1016/j.tree.2014.06.004

Gristina M, Sinopoli M, Fiorentino F, Garofalo G, Badalamenti F. 2011. Shelter selection of the spiny lobster Palinurus elephas under different levels of Octopus vulgaris predation threat. Mar Biol. 158(6):1331-1337. https://doi.org/10.1007/s00227-011-1652-4

Guibé M, Boal JG, Dickel L. 2010. Early exposure to odors changes later visual prey preferences in cuttlefish. Dev Psychobiol. 52(8):833-837. https://doi.org/10.1002/dev.20470

Hair C, Militz T, Daniels N, Southgate PC. 2020. Comparison of survival, growth and burying behavior of cultured and wild sandfish (Holothuria scabra) juveniles: implications for ocean mariculture. Aquaculture. 526:735355. https://doi.org/10.1016/j.aquaculture.2020.735355 
Härkönen L, Hyvärinen P, Paappanen J, Vainikka A. 2014. Explorative behavior increases vulnerability to angling in hatchery-reared brown trout (Salmo trutta). Can J Fish Aquat Sci. 71(12):1900-1909. https://doi.org/10.1139/cjfas-2014-0221

Harvey MC, Brown GE. 2004. Dine or dash?: ontogentic shift in the response of yellow perch to conspecific alarm cues. Environ Biol Fish. 70(4):345-352. https://doi. org/10.1023/B:EBFI.0000035432.12313.87

Hatanpää A, Huuskonen H, Kekäläinen J, Kortet R, Hyvärinen P, Vitelletti ML, Piironen J. 2020. Early winter foraging success, swimming performance, and morphology of juvenile landlocked Atlantic salmon reared under semi-wild and hatchery conditions. Can J Fish Aquat Sci. 77(4):770-778. https://doi.org/10.1139/cjfas-2019-0079

Havel JE, Kovalenko KE, Thomaz SM, Amalfitano S, Kats LB. 2015. Aquatic invasive species: challenges for the future. Hydrobiologia. 750(1):147-170. https://doi.org/10.1007/ s10750-014-2166-0

Hawkins LA, Armstrong JD, Magurran AE. 2007. A test of how predator conditioning influences survival of hatchery-reared Atlantic salmon, Salmo salar, in restocking programmes. Fish Manag Ecol. 14:291-293. https://doi.org/10.1111/j.1365-2400.2007.00548.x

Hawkins LA, Magurran AE, Armstrong JD. 2008. Ontogenetic learning of predator recognition in hatchery-reared Atlantic salmon, Salmo salar. Anim Behav. 75(5):1663-1671. https:// doi.org/10.1016/j.anbehav.2007.10.019

Henderson HF. 1980. Behavioral adjustment of fishes to release into a new habitat. In: Bardach JE, Magnuson JJ, May RC, Reinhart JM, editors. Fish behavior and its use in the capture and culture of fishes. Manila: ICLARM. p. 331-344.

Hendry AP, Schoen DJ, Wolak ME, Reid JM. 2018. The contemporary evolution of fitness. Annu Rev Ecol Evol Syst. 49:457-476. https://doi.org/10.1146/annurev-ecolsys-110617-062358

Hervas S, Lorenzen K, Shane MA, Drawbridge MA. 2010. Quantitative assessment of a white seabass (Atractoscion nobilis) stock enhancement program in California: post-release dispersal, growth and survival. Fish Res. 105(3):237-243. https://doi.org/10.1016/j. fishres.2010.06.001

Hopley CW, Mathews SB, Appleby AE, Rankis A, Halliday KL. 1993. Effects of pond stocking rate on coho salmon survival at two Lower Columbia River fish hatcheries. Prog Fish-Cult. 55(1):16-28. https://doi.org/10.1577/1548-8640(1993)055<0016:EOPSRO>2.3.CO;2

Hossain MAR, Tanaka M, Masuda R. 2002. Predator-prey interaction between hatchery-reared Japanese flounder juvenile, Paralichthys olivaceus, and sandy shore crab, Matuta lunaris: daily rhythms, anti-predator conditioning and starvation. J Exp Mar Biol Ecol. 267(1):1-14. https://doi.org/10.1016/S0022-0981(01)00340-9

Huntingford FA. 2004. Implications of domestication and rearing conditions for the behaviour of cultivated fishes. J Fish Biol. 65:122-142. https://doi.org/10.1111/j.0022-1112.2004.00562.x

Hutchison M, Butcher A, Norris A, Kirkwood J, Chilcott K. 2012a. A review of domestication effects on stocked fishes, strategies to improve post stocking survival of fishes and their potential application to threatened fish species recovery programs in the Murray-Darling Basin. Report to the Murray-Darling Basin Commission, No 48/12. Murray-Darling Basin Authority.

Hutchison M, Stewart D, Chilcott K, Butcher A, Henderson A, McLennan M, Smith P. 2012 b. Strategies to improve post release survival of hatchery-reared threatened fish species. Report to the Murray-Darling Basin Commission, No 135/11. Murray-Darling Basin Authority.

Hyvärinen P, Rodewald P. 2013. Enriched rearing improves survival of hatchery-reared Atlantic salmon smolts during migration in the River Tornionjoki. Can J Fish Aquat Sci. 70(9):13861395. https://doi.org/10.1139/cjfas-2013-0147

ICES. 2019. Atlantic salmon (Salmo salar) in subdivisions 22-31 (Baltic Sea, excluding the Gulf of Finland). ICES Advice on fishing opportunities, catch, and effort, Baltic Sea Ecoregion. No. sal.27.22-31. https://doi.org/10.17895/ices.advice.4742 
Islam SS, Wringe BF, Bradbury IR, Fleming IA. 2020. Behavioural variation among divergent European and North American farmed and wild Atlantic salmon (Salmo salar) populations. Appl Anim Behav Sci. 230:105029. https://doi.org/10.1016/j.applanim.2020.105029

Jackson LA, Rakocinski CF, Blaylock RB. 2015. Previous exposure to novel prey improves the feeding success of hatchery-reared spotted seatrout, Cynoscion nebulosus (Cuvier, 1830) within habitat structure. Aquacult Res. 46(12):3079-3083. https://doi.org/10.1111/ are. 12438

Järvi T, Uglem I. 1993. Predator training improves the anti-predator behaviour of hatchery reared Atlantic salmon (Salmo salar) smolt. Nord J Freshw Res. 68:63-71.

Jenkins TM. 1971. Role of social behavior in dispersal of introduced rainbow trout (Salmo gairdneri). J Fish Res Board Can. 28(7):1019-1027. https://doi.org/10.1139/f71-148

Johnsson JI, Brockmark S, Näslund J. 2014. Environmental effects on behavioural development: consequences for fitness of captive-reared fish in the wild. J Fish Biol. 85(6):1946-1971. https://doi.org/10.1111/jfb.12547

Johnsson JI, Näslund J. 2018. Studying behavioural variation in salmonids from an ecological perspective: observations, questions, methodological considerations. Rev Fish Biol Fish. 28(4):795-823. https://doi.org/10.1007/s11160-018-9532-3

Jolles JW, Boogert NJ, Sridhar VH, Couzin ID, Manica A. 2017. Consistent individual differences drive collective behavior and group functioning of schooling fish. Curr Biol. 27(18):2862-2868. https://doi.org/10.1016/j.cub.2017.08.004

Jonsson B, Jonsson N. 2014. Early environment influences later performance in fishes. J Fish Biol. 85(2):151-188. https://doi.org/10.1111/jfb.12432

Jonsson B, Jonsson N, Hansen LP. 1990. Does juvenile experience affect migration and spawning of adult Atlantic salmon? Behav Ecol Sociobiol. 26(4):225-230. https://doi.org/10.1007/ BF00178315

Justome B, Rochette R, Himmelman JH. 1998. Investigation of the influence of exposure to predation risk on the development of defensive behaviors in a marine gastropod. Veliger. 41(2):172-179.

Kaas JH, editor. 2017. Evolution of nervous systems. 2nd Ed. Oxford: Academic Press.

Kanayama Y. 1968. Studies of the conditioned reflex in lower vertebrates. X. Defensive conditioned reflex of chum salmon fry in group. Mar Biol. 2:77-87. https://doi.org/10.1007/ BF00351643

Kaneko S, Masuda R, Yamashita Y. 2019. Memory retention capacity using two different training methods, appetitive and aversive learning, in juvenile red sea bream Chrysophrys major. J Fish Biol. 94(2):231-240. https://doi.org/10.1111/jfb.13876

Kanidyev AN, Kostyunin GM, Salmin SA. 1970. Hatchery propagation of the pink and chum almon as a means of increasing the salmon stocks of Sakhalin. J Ichthyol. 10:249-259.

Karplus I, Katzenstein R, Goren M. 2006. Predator recognition and social facilitation of predator avoidance in coral reef fish Dascyllus marginatus juveniles. Mar Ecol Progr Ser. 319:215223. https://doi.org/10.3354/meps319215

Kavanagh M, Olson DE. 2014. The effects of rearing density on growth, fin erosion, survival, and migration behavior of hatchery winter steelhead. N Am J Aquacult. 76(4):323-332. https://doi.org/10.1080/15222055.2014.920747

Kawabata Y, Asami K, Kobayashi M, Sato T, Okuzawa K, Yamada H, Yoseda K, Arai N. 2011a. Effect of shelter acclimation on the postrelease movement and putative predation mortality of hatchery-reared black-spot tuskfish Choerodon schoenleinii, determined by acoustic telemetry. Fish Sci. 77(3):345-355. https://doi.org/10.1007/s12562-011-0351-x

Kawabata Y, Asami K, Kobayashi M, Sato T, Okuzawa K, Yamada H, Yoseda K, Arai N. 2011b. Effect of shelter acclimation on the postrelease survival of hatchery-reared black-spot tuskfish Choerodon schoenleinii: laboratory experiments using the reef-resident predator white-streaked grouper Epinephelus ongus. Fish Sci. 77(1):79-85. https://doi.org/10.1007/ s12562-010-0313-8 
Keil WM. 1935. Better stocking methods. Prog Fish-Cult. 2(9):1-6. https://doi. org/10.1577/1548-8640(1935)29[1:BSM]2.0.CO;2

Kelley JL, Magurran AE. 2003. Learned predator recognition and antipredator responses in fishes. Fish Fish. 4(3):216-226. https://doi.org/10.1046/j.1467-2979.2003.00126.x

Kelley JL, Magurran AE, Macías-Garcia C. 2005. The influence of rearing experience on the behaviour of an endangered Mexican fish, Skiffia multipunctata. Biol Conserv. 122(2):223230. https://doi.org/10.1016/j.biocon.2004.07.011

Kellison GT, Eggleston DB, Burke JS. 2000. Comparative behaviour and survival of hatchery-reared versus wild summer flounder (Paralichthys dentatus). Can J Fish Aquat Sci. 57(9):1870-1877. https://doi.org/10.1139/f00-139

Kelly CD. 2006. Replicating empirical research in behavioral ecology: how and why it should be done but rarely ever is. Q Rev Biol. 81(3):221-236. https://doi.org/10.1086/506236

Kieffer JD. 2010. Perspective - exercise in fish: 50+ years and going strong. Comp Biochem Physiol A Mol Integr Physiol. 156(2):163-168. https://doi.org/10.1016/j.cbpa.2010.02.009

Kieffer JD, Colgan PW. 1992. The role of learning in fish behaviour. Rev Fish Biol Fish. 2(2):125143. https://doi.org/10.1007/BF00042881

Kihslinger RL, Nevitt GA. 2006. Early rearing environment impacts cerebellar growth in juvenile salmon. J Exp Biol. 209(3):504-509. https://doi.org/10.1242/jeb.02019

Kleiman DG. 1989. Reintroduction of captive mammals for conservation. BioScience. 39(3):152-161. https://doi.org/10.2307/1311025

Koeck B, Závorka L, Aldvén D, Näslund J, Arlinghaus R, Thörnqvist P-O, Winberg S, Björnsson BTh, Johnsson JI. 2019. Angling selects against active and stress-resilient phenotypes in rainbow trout. Can J Fish Aquat Sci. 76(2):320-333. https://doi.org/10.1139/cjfas-2018-0085

Kopack CJ, Broder ED, Fetherman ER, Lepak JM, Angeloni LM. 2016. The effect of a single prerelease exposure to conspecific alarm cue on poststocking survival in three strains of rainbow trout (Oncorhynchus mykiss). Can J Zool. 94(9):661-664. https://doi.org/10.1139/ cjz-2016-0086

Kotrschal A, Buechel SD, Zala SM, Corral-Lopez A, Penn DJ, Kolm N. 2015. Brain size affects female but not male survival under predation. Ecol Lett. 18(7):646-652. https://doi. org/10.1111/ele.12441

Kotrschal A, Kotrschal K. 2020. Fish brains: anatomy, functionality, and evolutionary relationships. In: Kristiansen TS, Fernö A, Pavlidis MA, van de Vis H, editors. The welfare of fish. Cham: Springer Nature Switzerland AG. p. 129-148.

Kotrschal K, van Staaden MJ, Huber R. 1998. Fish brains: evolution and environmental relationships. Rev Fish Biol Fish. 8(4):373-408. https://doi.org/10.1023/A:1008839605380

Krepski T, Czerniawski R. 2019. Can we teach a fish how to eat? The impact of bottom and surface feeding on survival and growth of hatchery-reared sea trout parr (Salmo trutta trutta L.) in the wild. PLOS ONE. 14:e0222182. https://doi.org/10.1371/journal.pone.0222182

Kristensen LD, Sparrevohn CR, Christensen JT, Støttrup JG. 2014. Cryptic behaviour of juvenile turbot Psetta maxima L. and European flounder Platichthys flesus L. Open J Mar Sci. 4(3):185-193. https://doi.org/10.4236/ojms.2014.43018

Larsen MH, Johnsson JI, Näslund J, Thomassen ST, Aarestrup K. 2016. Reduced rearing density increases postrelease migration success of Atlantic salmon (Salmo salar) smolts. Can J Fish Aquat Sci. 73(5):804-810. https://doi.org/10.1139/cjfas-2014-0563

Lebata-Ramos MJH, Doyola-Solis EFC, Abrogueña JBR, Ogata H, Sumbing JG, Sibonga RC. 2013. Evaluation of postrelease behavior, recapture, and growth rates of hatchery-reared abalone Haliotis asinina released in Sagay Marine Reserve, Philippines. Rev Fish Sci. 21(34):433-440. https://doi.org/10.1080/10641262.2013.836445

Lee JSF, Berejikian BA. 2008. Effects of the rearing environment on average behaviour and behavioural variation in steelhead. J Fish Biol. 72(7):1736-1749. https://doi. org/10.1111/j.1095-8649.2008.01848.x 
Lee Y-H, Yan HY, Chiao C-C. 2012. Effects of early visual experience on the background preference in juvenile cuttlefish Sepia pharaonis. Biol Lett. 8(5):740-743. https://doi.org/10.1098/ rsbl.2012.0398

Lees KJ, MacNeil MA, Hedges KJ, Hussey NE. 2021. Estimating demographic parameters for fisheries management using acoustic telemetry. Rev Fish Biol Fish. 31:25-51. https://doi. org/10.1007/s11160-020-09626-8

Lema SC, Gumm JM, Feuerbacher OG, Schwemm MR. 2021. Assisting recovery: intensive interventions to conserve native fishes of desert springs and wetlands. In: Propst D, Williams J, Bestgen K, Hoagstrom C, editors. Standing between life and extinction. Chicago: University of Chicago Press. p. 335-352.

Lennox RJ, Aarestrup K, Cooke SJ, Cowley PD, Deng ZD, Fisk AT, Harcourt RG, Heupel M, Hinch SG, Holland KN, et al. 2017. Envisioning the future of aquatic animal tracking: technology, science, and application. BioScience. 67(10):884-896. https://doi.org/10.1093/ biosci/bix098

Le Vay L, Carvalho GR, Quinitio ET, Lebata JH, Ut VN, Fushimi H. 2007. Quality of hatcheryreared juveniles for marine fisheries stock enhancement. Aquaculture. 268(1-4):169-180. https://doi.org/10.1016/j.aquaculture.2007.04.041

Levitis AD, Lidicker WZ, Freund G. 2009. Behavioural biologists do not agree on what constitutes behaviour. Anim Behav. 78(1):103-110. https://doi.org/10.1016/j.anbehav.2009.03.018

Long WC, Cummiskey PA, Munk JE. 2018. How does stocking density affect enhancement success for hatchery-reared red king crab? Can J Fish Aquat Sci. 75(11):1940-1948. https:// doi.org/10.1139/cjfas-2017-0330

Lord RF. 1934. Hatchery trout as foragers and game fish. Trans Am Fish Soc. 64(1):339-345. https://doi.org/10.1577/1548-8659(1934)64[339:HTAFAG]2.0.CO;2

Lorenzen K. 2006. Population management in fisheries enhancement: gaining key information from release experiments through use of a size-dependent mortality model. Fish Res. 80:19-27. https://doi.org/10.1016/j.fishres.2006.03.010

Lorenzen K, Beveridge MCM, Mangel M. 2012. Cultured fish: integrative biology and management of domestication and interactions with wild fish. Biol Rev. 87(3):639-660. https://doi. org/10.1111/j.1469-185X.2011.00215.x

Lorenzen K, Leber KM, Blankenship HL. 2010. Responsible approach to marine stock enhancement: an update. Rev Fish Sci. 18(2):189-210. https://doi.org/10.1080/10641262.20 10.491564

Lovén Wallerius M, Gräns A, Koeck B, Berger D, Sandblom E, Ekström A, Arlinghaus R, Johnsson JI. 2019. Socially induced stress and behavioural inhibition in response to angling exposure in rainbow trout. Fish Manag Ecol. 26:611-620. https://doi.org/10.1111/ fme.12373

Lovén Wallerius M, Johnsson JI, Cooke SJ, Arlinghaus R. 2020. Hook avoidance induced by private and social learning in common carp. Trans Am Fish Soc. 149:498-511. https://doi. org/10.1002/tafs.10246

Lü H, Chapelsky A, Fu M, Xi D, Zhang Z, Zhang X. 2018. Effect of sand grain size on substrate preference and burial behaviour in cultured Japanese flounder juvenile, Paralichthys olivaceus. Aquacult Res. 49(4):1664-1671. https://doi.org/10.1111/are.13622

Makino H, Masuda R, Tanaka M. 2015. Environmental stimuli improve learning capability in striped knifejaw juveniles: the stage-specific effect of environmental enrichment and the comparison between wild and hatchery-reared fish. Fish Sci. 81(6):1035-1042. https://doi. org/10.1007/s12562-015-0917-0

Malavasi S, Georgalas V, Lugli M, Torricelli P, Mainardi D. 2004. Differences in the pattern of antipredator behaviour between hatchery-reared and wild European sea bass juveniles. J Fish Biol. 65(Suppl A):143-155. https://doi.org/10.1111/j.0022-1112.2004.00545.x

Marsh PC, Kesner BR, Pacey CA. 2005. Repatriation as a management strategy to conserve a critically imperiled fish species. N Am J Fish Manag. 25(2):547-556. https://doi. org/10.1577/M04-123.1 
Martin CW. 2014. Naïve prey exhibit reduced antipredator behavior and survivorship. PeerJ. 2:e665. https://doi.org/10.7717/peerj.665

Martin RM, Wertheimer A. 1989. Adult production of chinook salmon reared at different densities and released as two smolt sizes. Prog Fish-Cult. 51(4):194-200. https://doi. org/10.1577/1548-8640(1989)051<0194:APOCSR >2.3.CO;2

Massee KC, Kim J, Berejikian BA, Hardy RW. 2007. Prey selection and efficiency of naïve and experienced juvenile sockeye salmon. J Fish Biol. 70(4):1213-1223. https://doi. org/10.1111/j.1095-8649.2007.01389.x

Masuda R. 2004. Behavioral approaches to fish stock enhancement: a practical review. In: Leber KM, Kitada S, Blankenship HL, Svåsand T, editors. Stock enhancement and sea ranching: developments, pitfalls, and opportunities. 2nd ed. Oxford: Blackwell Publishing Ltd. p. 83-90.

Maynard DJ, McDowell GC, Tezak EP, Flagg TA. 1996. Effect of diets supplemented with live food on the foraging behavior of cultured fall chinook salmon. Prog Fish-Cult. 58(3):187191. https://doi.org/10.1577/1548-8640(1996)058<0187:EODSWL >2.3.CO;2

McNeil WJ. 1991. Expansion of cultured Pacific salmon into marine ecosystems. Aquaculture. 98(1-3):173-183. https://doi.org/10.1016/0044-8486(91)90382-H

Melnychuk MC, Korman J, Hausch S, Welch DW, McCubbing DJF, Walters CJ. 2014. Marine survival difference between wild and hatchery-reared steelhead trout determined during early downstream migration. Can J Fish Aquat Sci. 71(6):831-846. https://doi.org/10.1139/ cjfas-2013-0165

Menzel R, Brembs B, Giurfa M. 2007. Cognition in invertebrates. In: Kaas JH, editor. Evolution of nervous systems. Oxford: Academic Press. p. 403-422.

Mery F, Kawecki TJ. 2004. The effect of learning on experimental evolution of resource preference in Drosophila melanogaster. Evolution. 58(4):757-767. https://doi. org/10.1111/j.0014-3820.2004.tb00409.x

Mes D, van Os R, Gorissen M, Ebbesson LOE, Finstad B, Mayer I, Vindas M. 2019. Effects of environmental enrichment on forebrain neural plasticity and survival success of stocked Atlantic salmon. J Exp Biol. 222:jeb212258. https://doi.org/10.1242/jeb.212258

Mesa MG. 1991. Variation in feeding, aggression, and position choice between hatchery and wild cutthroat trout in an artificial stream. Trans Am Fish Soc. 120(6):723-727. https://doi. org/10.1577/1548-8659(1991)120<0723:VIFAAP >2.3.CO;2

Mesquita F de O, Young RJ. 2007. The behavioural responses of Nile tilapia (Oreochromis niloticus) to anti-predator training. Appl Anim Behav Sci. 106:144-154. https://doi. org/10.1016/j.applanim.2006.06.013

Metcalfe NB. 1990. Aquaculture. In: Monaghan P, Wood-Gush D, editors. Managing the behaviour of animals. London: Chapman \& Hall. p. 125-154.

Metcalfe NB, Valdimarsson SK, Morgan IJ. 2003. The relative roles of domestication, rearing environment, prior residence and body size in deciding territorial contests between hatchery and wild juvenile salmon. J Appl Ecol. 40(3):535-544. https://doi. org/10.1046/j.1365-2664.2003.00815.x

Milinski M. 1993. Predation risk and feeding behavior. In: Pitcher TJ, editor. Behaviour of teleost fishes. 2nd ed. London: Chapman \& Hall. p. 285-305.

Mirza RS, Chivers DP. 2000. Predator-recognition training enhances survival of brook trout: evidence from laboratory and field enclosure studies. Can J Zool. 78(12):2198-2208. https://doi.org/10.1139/z00-164

Mittelbach GG, Ballew NG, Kjelvik MK. 2014. Fish behavioral types and their ecological consequences. Can J Fish Aquat Sci. 71(6):927-944. https://doi.org/10.1139/cjfas-2013-0558

Moberg O, Braithwaite VA, Jensen KH, Salvanes AGV. 2011. Effects of habitat enrichment and food availability on the foraging behaviour of juvenile Atlantic cod (Gadus morhua L.). Environ Biol Fish. 91(4):449-457. https://doi.org/10.1007/s10641-011-9803-5

Monk CT, Chéret B, Czapla P, Hühn D, Klefoth T, Eschbach E, Hagemann R, Arlinghaus R. 2020. Behavioural and fitness effects of translocation to a novel environment: whole-lake 
experiments in two aquatic top predators. J Anim Ecol. 89(10):2325-2344. https://doi. org/10.1111/1365-2656.13298

Moore M, Berejikian BA, Tezak EP. 2012. Variation in early marine survival and behavior of natural and hatchery-reared Hood Canal steelhead. PLOS ONE. 7(11):e49645. https://doi. org/10.1371/journal.pone.0049645

Mueller GA, Carpenter J, Krapfel R, Figiel C. 2007. Preliminary testing of the role of exercise and predator recognition for bonytail and razorback sucker. US Geological Survey OpenFile Report 2007-1423. 37 p.

Mundie JH, Mounce DE, Simpson KS. 1990. Semi-natural rearing of coho salmon, Oncorhynchus kisutch (Walbaum), smolts, with an assessment of survival to the catch and escapement. Aquacult Fish Manag. 21:327-346. https://doi.org/10.1111/j.1365-2109.1990.tb00471.x

Nakagawa S, Poulin R, Mengersen K, Reinhold K, Engqvist L, Lagisz M, Senior AM. 2015. Meta-analysis of variation: ecological and evolutionary applications and beyond. Methods Ecol Evol. 6(2):143-152. https://doi.org/10.1111/2041-210X.12309

Näslund I. 1992. Survival and distribution of pond- and hatchery-reared 0+ brown trout, Salmo trutta L., released in a Swedish stream. Aquacult Fish Manag. 23:477-488. https:// doi.org/10.1111/j.1365-2109.1992.tb00791.x

Näslund J, Johnsson JI. 2016. Environmental enrichment for fish in captive environments: effects of physical structures and substrates. Fish Fish. 17(1):1-30. https://doi.org/10.1111/ faf.12088

Näslund J, Larsen MH, Thomassen ST, Aarestrup K, Johnsson JI. 2017. Environment-dependent plasticity and ontogenetic changes in the brain of hatchery-reared Atlantic salmon. J Zool (Lond). 301(1):75-82. https://doi.org/10.1111/jzo.12392

Näslund J, Rosengren M, Del Villar D, Gansel L, Norrgård JR, Persson L, Winkowski JJ, Kvingedal E. 2013. Hatchery tank enrichment affects cortisol levels and shelter-seeking in Atlantic salmon (Salmo salar). Can J Fish Aquat Sci. 70(4):585-590. https://doi. org/10.1139/cjfas-2012-0302

Näslund J, Rosengren M, Johnsson JI. 2019. Fish density, but not environmental enrichment, affects the size of cerebellum in the brain of juvenile hatchery-reared Atlantic salmon. Environ Biol Fish. 102(5):705-712. https://doi.org/10.1007/s10641-019-00864-9

Niemelä PT, Vainikka A, Forsman JT, Loukola OJ, Kortet R. 2013. How does variation in the environment and individual cognition explain the existence of consistent behavioral differences? Ecol Evol. 3(2):457-464. https://doi.org/10.1002/ece3.451

Niven JE, Laughlin SB. 2008. Energy limitation as a selective pressure on the evolution of sensory systems. J Exp Biol. 211:1792-1804. https://doi.org/10.1242/jeb.017574

Nordeide JT, Salvanes AGV. 1991. Observations on reared newly released and wild cod (Gadus morhua L.) and their potential predators. ICES Mar Sci Symp. 192:139-146.

Norris AJ. 2004. Sensory modalities, plasticity and prey choice in three sympatric species of whiting (Pisces: Sillaginidae), PhD Thesis, Centre for Marine Studies, University of Queensland.

Ochwada-Doyle F, Gray CA, Loneragan NR, Taylor MD. 2010. Using experimental ecology to understand stock enhancement: comparisons of habitat-related predation on wild and hatchery-reared Penaeus plebejus Hess. J Exp Mar Biol Ecol. 390:65-71. https://doi. org/10.1016/j.jembe.2010.04.003

Oliver MD, MacDiarmid AB, Stewart RA, Gardner C. 2006. Spiny lobster population enhancement: moderation of emergence behaviour of juvenile Jasus edwardsii reared in captivity. N Z J Mar Freshw Res. 40(4):605-613. https://doi.org/10.1080/00288330.2006.9517449

Olla BL, Davis MW. 1989. The role of learning and stress in predator avoidance of hatcheryreared coho salmon (Oncorhynchus kisutch) juveniles. Aquaculture. 76(3-4):209-214. https://doi.org/10.1016/0044-8486(89)90075-6

Olla BL, Davis MW, Ryer CH. 1998. Understanding how the hatchery environment represses or promotes the development of behavioural survival skills. Bull Mar Sci. 62(2):531-550. 
Olson JA, Olson JM, Walsh RE, Wisenden BD. 2012. A method to train groups of predator-naive fish to recognize and respond to predators when released into the natural environment. N Am J Fish Manag. 32:77-81. https://doi.org/10.1080/02755947.2012.661390

Orlov AV, Gerasimov YV, Lapshin OM. 2006. The feeding behaviour of cultured and wild Atlantic salmon, Salmo salar L., in the Louvenga River, Kola Peninsula, Russia. ICES J Mar Sci. 63(7):1297-1303. https://doi.org/10.1016/j.icesjms.2006.05.004

Orr MV, Hittel K, Lukowiak K. 2008. Comparing memory-forming capabilities between laboratory-reared and wild Lymnaea: learning in the wild, a heritable component of snail memory. J Exp Biol. 211:2807-2816. https://doi.org/10.1242/jeb.020172

Östergren J, Palm S, Gilbey J, Spong G, Dannewitz J, Königsson H, Persson J, Vasemägi A. 2021. A century of genetic homogenization in Baltic salmon - evidence from archival DNA. Proc R Soc Lond B. 288:20203147. https://doi.org/10.1098/rspb.2020.3147

Parkes L, Quinitio ET, Le Vay L. 2011. Phenotypic differences between hatchery-reared and wild mud crabs, Scylla serrata, and the effects of conditioning. Aquacult Int. 19(2):361380. https://doi.org/10.1007/s10499-010-9372-1

Paszkowski CA, Olla BL. 1985. Foraging behavior of hatchery-produced coho salmon (Oncorhynchus kisutch) smolts on live prey. Can J Fish Aquat Sci. 42(12):1915-1921. https://doi.org/10.1139/f85-237

Patten BG. 1977. Body size and learned avoidance as factors affecting predation on coho salmon, Oncorhynchus kisutch, fry by torrent sculpin, Cottus rhotheus. Fish Bull. 75:457-459.

Pavlov IP. 1927. Conditioned reflexes. New York: Dover.

Persson L, Leonardsson K, Alanärä A. 2018. Manipulation of the energetic state of Atlantic salmon Salmo salar juveniles and the effect on migration speed. J Fish Biol. 92(4):961-978. https://doi.org/10.1111/jfb.13555

Petersson E, Valencia AC, Järvi T. 2015. Failure of predator conditioning: an experimental study of predator avoidance in brown trout (Salmo trutta). Ecol Freshw Fish. 24:329-337. https://doi.org/10.1111/eff.12146

Pflugfelder O. 1952. Weitere volumetrische Untersuchungen über die Wirkung der Augenextirpation und der Dunkelhaltung auf das Mesencephalon und die Pseudobranchien von Fischen. Wilhelm Roux'. Arch Entwicklungsmech Org. 145:549-560. [In German]. https:// doi.org/10.1007/BF00575535

Poh B, Tweedley JR, Chaplin JA, Trayler KM, Loneragan NR. 2018. Estimating predation rates of restocked individuals: the influence of timing-of-release on metapenaeid survival. Fish Res. 198:165-179. https://doi.org/10.1016/j.fishres.2017.09.019

Poirier R, Chichery R, Dickel L. 2004. Effects of rearing conditions on sand digging efficiency in juvenile cuttlefish. Behav Processes. 67(2):273-279. https://doi.org/10.1016/j. beproc.2004.04.006

Poirier R, Chichery R, Dickel L. 2005. Early experience and postembryonic maturation of body patterns in cuttlefish (Sepia officinalis). J Comp Psychol. 119(2):230-237. https://doi. org/10.1037/0735-7036.119.2.230

Rae DL, Mos B, Scott A, Dworjanyn SA. 2020. Training fish for restocking: refuge and predator training in the hatchery has limited benefits for a marine fish. J Fish Biol. 97(1):172-182. https://doi.org/10.1111/jfb.14345

Reiriz L, Nicieza AG, Braña F. 1998. Prey selection by experienced and naive juvenile Atlantic salmon. J Fish Biol. 53(1):100-114. https://doi.org/10.1111/j.1095-8649.1998.tb00113.x

Rescorla RA, Wagner AR. 1972. A theory of Pavlovian conditioning: variations in the effectiveness of reinforcement and nonreinforcement. In: Black AH, Prokasy WF, editors. Classical conditioning II. New York: Appleton-Century-Crofts. p. 64-99.

Riley SC, Tatara CP, Berejikian BA, Flagg TA. 2009. Behavior of steelhead fry in a laboratory stream is affected by fish density but not rearing environment. N Am J Fish Manag. 29(6):1806-1818. https://doi.org/10.1577/M09-035.1 
Rivi V, Benatti C, Lukowiak K, Colliva C, Alboni S, Tascedda F, Blom JMC. 2021. What can we teach Lymnaea and what can Lymnaea tech us? Biol Rev Camb Philos Soc. https://doi. org/10.1111/brv.12716

Roberts LJ, Taylor J, Garcia de Leaniz C. 2011. Environmental enrichment reduces maladaptive risk-taking behavior in salmon reared for conservation. Biol Conserv. 144(7):1972-1979. https://doi.org/10.1016/j.biocon.2011.04.017

Roberts LJ, Taylor J, Gough PJ, Forman DW, Garcia de Leaniz C. 2014. Silver spoons in the rough: can environmental enrichment improve survival of hatchery Atlantic salmon Salmo salar in the wild? J Fish Biol. 85(6):1972-1991. https://doi.org/10.1111/jfb.12544

Robertson A. 1919. Hatching fry in gravel. Trans Am Fish Soc. 48:146-156. https://doi. org/10.1577/1548-8659(1918)48[146:HFIG]2.0.CO;2

Rochette R, Arsenault DJ, Justome B, Himmelman JH. 1998. Chemically-mediated predatorrecognition learning in a marine gastropod. Ecoscience. 5(3):353-360. https://doi.org/10.1 080/11956860.1998.11682473

Rodewald P, Hyvärinen P, Hirvonen H. 2011. Wild origin and enriched environment promote foraging rate and learning to forage on natural prey of captive reared Atlantic salmon parr. Ecol Freshw Fish. 20(4):569-579. https://doi.org/10.1111/j.1600-0633.2011.00505.x

Rosengren M, Kvingedal E, Näslund J, Johnsson JI, Sundell K. 2017. Born to be wild: effects of rearing density and environmental enrichment on stress, welfare, and smolt migration in hatchery-reared Atlantic salmon. Can J Fish Aquat Sci. 74(3):396-405. https://doi. org/10.1139/cjfas-2015-0515

Rowland WJ. 1999. Studying visual cues in fish behavior: a review of ethological techniques. Environ Biol Fish. 56(3):285-305. https://doi.org/10.1023/A:1007517720723

Salvanes AGV, Braithwaite VA. 2005. Exposure to variable spatial information in the early rearing environment generates asymmetries in social interactions in cod (Gadus morhua). Behav Ecol Sociobiol. 59(2):250-257. https://doi.org/10.1007/s00265-005-0031-x

Salvanes AGV, Braithwaite VA. 2006. The need to understand the behaviour of fish reared for mariculture or restocking. ICES J Mar Sci. 63(2):346-354. https://doi.org/10.1016/j. icesjms.2005.11.010

Salvanes AGV, Moberg O, Braithwaite VA. 2007. Effects of early experience on group behaviour in fish. Anim Behav. 74(4):805-811. https://doi.org/10.1016/j.anbehav.2007.02.007

Salvanes AGV, Moberg O, Ebbesson LOE, Nilsen TO, Jensen KH, Braithwaite VA. 2013. Environmental enrichment promotes neural plasticity and cognitive ability in fish. Proc $\mathrm{R}$ Soc B. 280:20131331. https://doi.org/10.1098/rspb.2013.1331

Sandeman R, Sandeman D. 2000. "Impoverished" and "enriched" living conditions influence the proliferation and survival of neurons in crayfish brain. J Neurobiol. 45(4):215-226. https://doi.org/10.1002/1097-4695(200012)45:4<215::AID-NEU3>3.0.CO;2-X

Schiel DR, Welden BC. 1987. Responses to predators of cultured and wild red abalone, Haliotis rufescens, in laboratory experiments. Aquaculture. 60(3-4):173-188. https://doi. org/10.1016/0044-8486(87)90286-9

Schuck HA. 1948. Survival of hatchery trout in streams and possible methods of improving the quality of hatchery trout. Prog Fish-Cult. 10(1):3-14. https://doi. org/10.1577/1548-8640(1948)10[3:SOHTIS]2.0.CO;2

Seebacher F, Ward AJW, Reid AL. 2010. Learning to hunt: the role of experience in predator success. Behaviour. 147(2):223-233. https://doi.org/10.1163/000579509X12512871386137

Self KE, Schreck CB, Cogliati KM, Billman EJ, Noakes DLG. 2018. The effect of rearing structures on behaviour and movement of juvenile steelhead Oncorhynchus mykiss. J Fish Biol. 93(3):449-454. https://doi.org/10.1111/jfb.13657

Shettleworth SJ. 2001. Animal cognition and animal behaviour. Anim Behav. 61(2):277-286. https://doi.org/10.1006/anbe.2000.1606

Shi X, Chen Q, Zhuang P, Liu D, Huang Y. 2012. Life skill trainings for hatchery fish to improve its foraging and antipredation capability in natural environments: a review. Shengtaixue Zazhi. 31(12):3235-3240. 
Shimizu D, Sakiyama K, Sakakura Y, Takatani T, Takahashi Y-I. 2008. Quantitative evaluation of postrelease mortality using salt pond mesocosms: case studies of hatchery and wild juvenile tiger puffer. Rev Fish Sci. 16(1-3):195-203. https://doi.org/10.1080/10641260701681755

Skinner BF. 1938. The behaviour of organisms: an experimental approach. New York: Appleton-Century.

Skov C, Koed A, Baastrup-Spohr L, Arlinghaus R. 2011. Dispersal, growth, and diet of stocked and wild northern pike fry in a shallow natural lake, with implications for the management of stocking programs. N Am J Fish Manag. 31(6):1177-1186. https://doi.org/10.1080/027 55947.2011 .646452

Slavík O, Horký P. 2021. Wild and farmed burbot Lota lota: differences in energy consumption and behavior during the spawning season. Aquacult Environ Interact. 13:51-63. https:// doi.org/10.3354/aei00389

Sloychuk JR, Chivers DP, Ferrari MCO. 2016. Juvenile lake sturgeon go to school: life-skills training for hatchery fish. Trans Am Fish Soc. 145(2):287-294. https://doi.org/10.1080/00 028487.2015.1123183

Solås MR, Skoglund H, Salvanes AGV. 2019. Can structural enrichment reduce predation mortality and increase recaptures of hatchery-reared Atlantic salmon Salmo salar L. fry released into the wild? J Fish Biol. 95(2):575-588. https://doi.org/10.1111/jfb.14004

Solberg MF, Robertsen G, Sundt-Hansen LE, Hindar K, Glover KA. 2020. Domestication leads to increased predation susceptibility. Sci Rep. 10:1929. https://doi.org/s41598-020-586619. https://doi.org/10.1038/s41598-020-58661-9

Sörensen J. 1919. Om kläckning och utplantering av olika fiskslag. Skrifter utgivna av Södra Sveriges Fiskeriförening 1919:68- 74. [In Swedish]

Sosiak AJ, Randall RG, McKenzie J A. 1979. Feeding by hatchery-reared and wild Atlantic salmon (Salmo salar) parr in streams. J Fish Board Can. 36(11):1408-1412. https://doi. org/10.1139/f79-202

Stearns SC. 1989. The evolutionary significance of phenotypic plasticity. BioScience. 39(7):436445. https://doi.org/10.2307/1311135

Stickney RR. 1994. Use of hatchery fish in enhancement programs. Fisheries. 19(5):6-13. https://doi.org/10.1577/1548-8446(1994)019<0006:UOHFIE >2.0.CO;2

Stoner AW. 1994. Significance of habitat and stock re-testing for enhancement of natural fisheries: experimental analyses with queen conch Strombus gigas. J World Aquacult Soc. 25(1):155-165. https://doi.org/10.1111/j.1749-7345.1994.tb00815.x

Stoner AW, Davis M. 1994. Experimental outplanting of juvenile queen conch, Strombus gigas: comparison of wild and hatchery-reared stocks. Fish Bull. 92(2):390-411.

Støttrup JG, Sparrevohn CR, Modin J, Lehmann K. 2002. The use of releases of reared fish to enhance natural populations: a case study on turbot Psetta maxima (Linné, 1758). Fish Res. 59(1-2):161-180. https://doi.org/10.1016/S0165-7836(01)00413-1

Stradmeyer L, Thorpe JE. 1987. Feeding behaviour of wild Atlantic salmon, Salmo salar L., parr in mid- to late summer in a Scottish river. Aquacult Fish Managem, 18(1):33-49. https:// doi.org/10.1111/j.1365-2109.1987.tb00123.x

Strand DA, Utne-Palm AC, Jakobsen PJ, Braithwaite VA, Salvanes AGV. 2010. Enrichment promotes learning in fish. Mar Ecol Prog Ser. 412:273-282. https://doi.org/10.3354/meps08682

Suboski MD, Templeton JJ. 1989. Life skills training for hatchery fish: social learning and survival. Fish Res. 7(4):343-352. https://doi.org/10.1016/0165-7836(89)90066-0

Sudo H, Kajihara N, Fujii T. 2008. Predation by the swimming crab Charybdis japonica and piscivorous fishes: a major mortality factor in hatchery-reared juvenile Japanese flounder Paralichthys olivaceus released in Mano Bay, Sado Island, Japan. Fish Res. 89(1):49-56. https://doi.org/10.1016/j.fishres.2007.08.012

Sundström LF, Johnsson JI. 2001. Experience and social environment influence the ability of young brown trout to forage on live novel prey. Anim Behav. 61(1):249-255. https://doi. org/10.1006/anbe.2000.1593 
Svåsand T, Skilbrei OT, van der Meeren GI, Holm M. 1998. Review of morphological and behavioural differences between reared and wild individuals: implications for sea-ranching of Atlantic salmon, Salmo salar L., Atlantic cod, Gadus morhua L., and European lobster, Homarus gammarus L. Fish Manag Ecol. 5(6):473-490. https://doi. org/10.1046/j.1365-2400.1998.560473.x

Szendrey TA, Wahl DH. 1995. Effect of feeding experience on growth, vulnerability to predation, and survival of esocids. N Am J Fish Manag. 15(3):610-620. https://doi. org/10.1577/1548-8675(1995)015<0610:EOFEOG>2.3.CO;2

Takahashi K, Masuda R. 2018. Net-chasing training improves the behavioral characteristics of hatchery-reared red sea bream (Pagrus major) juveniles. Can J Fish Aquat Sci. 75(6):861867. https://doi.org/10.1139/cjfas-2017-0073

Takahashi K, Masuda R. 2019. Nurture is above nature: nursery experience determines habitat preference of red sea bream Pagrus major juveniles. J Ethol. 37(3):317-323. https://doi. org/10.1007/s10164-019-00605-6

Takahashi K, Masuda R, Yamashita Y. 2013. Bottom feeding and net chasing improve foraging behavior in hatchery-reared Japanese flounder Paralichthys olivaceus juveniles for stocking. Fish Sci. 79(1):55-60. https://doi.org/10.1007/s12562-012-0572-7

Takahashi K, Masuda R, Yamashita Y. 2015. Can red sea bream Pagrus major learn about feeding and avoidance through the observation of conspecific behavior in video playback? Fish Sci. 81(4):679-685. https://doi.org/10.1007/s12562-015-0881-8

Tanaka Y, Yamaguchi H, Tominaga O, Tsusaki T, Tanaka M. 2006. Relationships between release season and feeding performance of hatchery-reared Japanese flounder Paralichthys olivaceus: in situ release experiment in coastal area of Wakasa Bay, Sea of Japan. J Exp Mar Biol Ecol. 330:511-520. https://doi.org/10.1016/j.jembe.2005.09.022

Tarrant RM. 1964. Rate of extinction of a conditioned response in juvenile sockeye salmon. Trans Am Fish Soc. 93(4):399-401. https://doi.org/10.1577/1548-8659(1964)93[399:ROE $\mathrm{OAC}] 2.0 . \mathrm{CO} ; 2$

Tatara CP, Riley SC, Scheurer JA. 2008. Environmental enrichment in steelhead (Oncorhynchus mykiss) hatcheries: field evaluation of aggression, foraging, and territoriality in natural and hatchery fry. Can J Fish Aquat Sci. 65(4):744-753. https://doi.org/10.1139/f08-004

Tatara CP, Riley SC, Scheurer JA. 2009. Growth, survival, and habitat use of naturally reared and hatchery steelhead fry in streams: effects of an enriched hatchery rearing environment. Trans Am Fish Soc. 138(3):441-457. https://doi.org/10.1577/T07-260.1

Taylor MD, Fielder DS, Suthers IM. 2009. Growth and viability of hatchery-reared Argyrosomus japonicus released into open and semi-closed systems. Fish Manag Ecol. 16(6):478-483. https://doi.org/10.1111/j.1365-2400.2009.00700.x

Teixeira A, Cortes RMV, Oliveira D. 2006. Habitat use by native and stocked trout (Salmo trutta) in two northeast streams, Portugal. Bull Fr Peche Piscicult. 382:1-18. https://doi. org/10.1051/kmae:2006004

Teletchea F. 2021. Fish domestication in aquaculture: 10 unanswered questions. Anim Front. 11:87-91. https://doi.org/10.1093/af/vfab012

Tetzlaff SJ, Sperry JH, DeGregorio BA. 2019. Effects of antipredator training, environmental enrichment, and soft release on wildlife translocations: a review and meta-analysis. Biol Conserv. 236:324-331. https://doi.org/10.1016/j.biocon.2019.05.054

Thompson BC, Porak WF, Leone EH, Allen MS. 2016. Using radiotelemetry to compare the initial behavior and mortality of hatchery-reared and wild juvenile Florida bass. Trans Am Fish Soc. 145(2):374-385. https://doi.org/10.1080/00028487.2015.1131739

Thompson RB. 1966. Effects of predator avoidance conditioning on postrelease survival rate of artificially propagated salmon. PhD thesis, University of Washington.

Tipping J, Byrne J, Hillson T. 2004. The effect of juvenile rearing density on adult returns of summer steelhead. N Am J Aquacult. 66(4):319-324. https://doi.org/10.1577/A04-010.1

Tomiyama T, Watanabe M, Kawata G, Ebe K. 2011. Postrelease performance and growth of hatchery-reared Japanese flounder Paralichthys olivaceus: relevance to stocking effectiveness. J Fish Biol. 78(5):1423-1436. https://doi.org/10.1111/j.1095-8649.2011.02949.x 
Trippel NA, Porak WF, Leone EH. 2018. Poststocking survival of conditioned and pond-reared compared to indoor pellet-reared advanced fingerling Florida bass. N Am J Fish Manag. 38(5):1039-1049. https://doi.org/10.1002/nafm.10213

Turek J, Randák T, Horký P, Zlábek V, Velišek J, Slavík O, Hanák R. 2010. Postrelease growth and dispersal of pond and hatchery-reared European grayling Thymallus thymallus compared with their wild conspecifics in a small stream. J Fish Biol. 76:684-693. https://doi. org/10.1111/j.1095-8649.2009.02526.x

Ullah I, Zuberi A, Khan KU, Ahmad S, Thörnqvist P-O, Winberg S. 2017. Effects of enrichment on the development of behaviour in an endangered fish mahseer (Tor putitora). Appl Anim Behav Sci. 186:93-100. https://doi.org/10.1016/j.applanim.2016.10.016

van der Meeren GI. 2001. Effects of experience with shelter in hatchery-reared juvenile European lobsters Homarus gammarus. Mar Freshw Res. 52(8):1487-1493. https://doi. org/10.1071/MF01067

Van Dyck H. 2012. Changing organisms in rapidly changing anthropogenic landscapes: the significance of the 'Umwelt'-concept and functional habitat for animal conservation. Evol Appl. 5(2):144-153. https://doi.org/10.1111/j.1752-4571.2011.00230.x

Vilhunen S. 2006. Repeated antipredator conditioning: a pathway to habituation or to better avoidance? J Fish Biol. 68(1):25-43. https://doi.org/10.1111/j.0022-1112.2006.00873.x

Vilhunen S, Hirvonen H. 2003. Innate antipredator responses of Arctic charr (Salvelinus alpinus) depend on predator species and their diet. Behav Ecol Sociobiol. 55(1):1-10. https://doi.org/10.1007/s00265-003-0670-8

Vilhunen S, Hirvonen H, Laakkonen MVM. 2005. Less is more: social learning of predator recognition requires a low demonstrator to observer ratio in Arctic charr (Salvelinus alpinus). Behav Ecol Sociobiol. 57(3):275-282. https://doi.org/10.1007/s00265-004-0846-x

Vincent RE. 1960. Some influences of domestication upon three stocks of brook trout (Salvelinus fontinalis Mitchill). Trans Am Fish Soc. 89(1):35-52. https://doi. org/10.1577/1548-8659(1960)89[35:SIODUT]2.0.CO;2

Vinyard GL, Drenner RW, Hanzel DA. 1982. Feeding success of hatchery-reared kokanee salmon when presented with zooplankton prey. Prog Fish-Cult. 44(1):37-39. https://doi. org/10.1577/1548-8659(1982)44[37:FSOHKS]2.0.CO;2

Vokoun JC, Noltie DB. 2002. Evidence for the inheritance of alarm substance recognition in Johnny darter (Etheostoma nigrum). Am Midl Nat. 147(2):400-403. https://doi. org/10.1674/0003-0031(2002)147[0400:EFTIOA]2.0.CO;2

Vollset K, Lennox R, Thorstad E, Auer S, Bär K, Larsen MH, Mahlum S, Näslund J, Stryhn H, Dohoo I. 2020. Systematic review and meta-analysis of PIT tagging effects on mortality and growth of juvenile salmonids. Rev Fish Biol Fish. 30:553-568. https://doi.org/10.1007/ s11160-020-09611-1

von Uexküll J. 1934. Streifzüge durch die Umwelten von Tieren und Menschen. Berlin: Verlag von Julius Springer. [In German].

Wahl DH, Einfalt LM, Hooe ML. 1995. Effect of experience with piscivory on foraging behavior and growth of walleyes. Trans Am Fish Soc. 124(5):756-763. https://doi. org/10.1577/1548-8659(1995)124<0756:EOEWPO >2.3.CO;2

Wahl DH, Einfalt LM, Wojcieszak DB. 2012. Effect of experience with predators on the behavior and survival of muskellunge and tiger muskellunge. Trans Am Fish Soc. 141(1):139-146. https://doi.org/10.1080/00028487.2011.652011

Wang S, Hard JJ, Utter F. 2002. Salmonid inbreeding: a review. Rev Fish Biol Fish. 11(4):301319. https://doi.org/10.1023/A:1021330500365

Warburton K, Hughes R. 2011. Learning of foraging skills by fish. In: Brown C, Laland K, Krause J, editors. Fish cognition and behavior. 2nd ed. London: Wiley-Blackwell. p. 10-35.

Ware DM. 1971. Predation by rainbow trout (Salmo gairdneri): the effect of experience. J Fish Res Board Can. 28(12):1847-1852. https://doi.org/10.1139/f71-279

Watters JV, Meehan CL. 2007. Different strokes: can managing behavioral types increase postrelease success? Appl Anim Behav Sci. 102(3-4):364-379. https://doi.org/10.1016/j. applanim.2006.05.036 
Watz J. 2019. Structural complexity in the hatchery rearing environment affects activity, resting metabolic rate and post-release behaviour in brown trout Salmo trutta. J Fish Biol. 95(2):638-641. https://doi.org/10.1111/jfb.14049

Watz J, Calles O, Carlsson N, Collin T, Huusko A, Johnsson J, Nilsson PA, Norrgård J, Nyqvist D. 2019. Wood addition in the hatchery and river environments affects postrelease performance of overwintering brown trout. Freshw Biol. 64(1):71-80. https://doi.org/10.1111/ fwb.13195

Wickins JF, Barry J. 1996. The effect of previous experience on the motivation to burrow in early benthic phase lobsters (Homarus gammarus (L.). Mar Freshwat Behav Physiol. 28(4):211228. https://doi.org/10.1080/10236249609378993

Wiley RW, Whaley RA, Satake JB, Fowden M. 1993. An evaluation of the potential for training trout in hatcheries to increase poststocking survival in streams. N Am J Fish Manag. 13(1):171-177. https://doi.org/10.1577/1548-8675(1993)013<0171:AEOTPF>2.3.CO;2

Wintzer AP, Motta PJ. 2005. A comparison of prey capture kinematics in hatchery and wild Micropterus salmoides floridanus: effects of ontogeny and experience. J Fish Biol. 67(2):409-427. https://doi.org/10.1111/j.0022-1112.2005.00748.x

Wisenden BD, Klitzke J, Nelson R, Friedl D, Jacobson PC. 2004. Predator-recognition training of hatchery-reared walleye (Stizostedion vitreum) and a field test of a training method using yellow perch (Perca flavescens). Can J Fish Aquat Sci. 61(11):2144-2150. https://doi. org/10.1139/f04-164

Wishingrad V, Sloychuk JR, Ferrari MCO, Chivers DP. 2014. Alarm cues in Lake Sturgeon Acipenser fulvescens Rafinesque, 1817: potential implications for life-skills training. J Appl Ichthyol. 30(6):1441-1444. https://doi.org/10.1111/jai.12580

Wright DE, Eastscott A. 1982. Operant conditioning of feeding behaviour and patterns of feeding in thick lipped mullet, Crenimugil labrosus (Risso) and common carp, Cyprinus carpio (L.). J Fish Biol. 20(6):625-634. https://doi.org/10.1111/j.1095-8649.1982.tb03972.x

Yamamoto T, Reinhardt U. 2003. Dominance and predator avoidance in domesticated and wild masu salmon Oncorhynchus masou. Fish Sci. 69(1):88-94. https://doi. org/10.1046/j.1444-2906.2003.00591.x

Yasumuro H, Ikeda Y. 2011. Effects of environmental enrichment on the behavior of the tropical octopus Callistoctopus aspilosomatis. Mar Freshw Behav Physiol. 44(3):143-157. https:// doi.org/10.1080/10236244.2011.598643

Yasumuro H, Ikeda Y. 2016. Environmental enrichment accelerates the ontogeny of cryptic behavior in pharaoh cuttlefish (Sepia pharaonis). Zool Sci. 33(3):255-265. https://doi. org/10.2108/zs150197

Young AC, Johnson EG, Davis JL, Hines AH, Zmora O, Zohar Y. 2008. Do hatchery-reared blue crabs differ from wild crabs, and does it matter? Rev Fish Sci. 16(1-3):254-261. https://doi. org/10.1080/10641260701684122

Young HS, McCauley DJ, Galetti M, Dirzo R. 2016. Patterns, causes, and consequences of anthropocene defaunation. Annu Rev Ecol Evol Syst. 47:333-358. https://doi.org/10.1146/ annurev-ecolsys-112414-054142

Zhang Z, Xu X, Wang Z, Zhang X. 2020. Effects of environmental enrichment on growth performance, aggressive behavior and stress-induced changes in cortisol release and neurogenesis of black rockfish Sebastes schlegelii. Aquaculture. 528:735483. https://doi. org/10.1016/j.aquaculture.2020.735483

Zhang Z, Zhang X, Li Z, Zhang X. 2019. Effects of different levels of environmental enrichment on the sheltering behaviors, brain development and cortisol levels of black rockfish Sebastes schlegelii. Appl Anim Behav Sci. 218:104825. https://doi.org/10.1016/j. applanim.2019.06.006

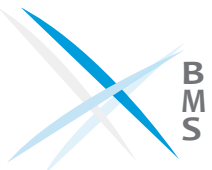

